NBER WORKING PAPERS SERIES

\title{
HABIT PERSISTENCE AND DURABILITY \\ IN AGGREGATE CONSUMPTION: \\ EMPIRICAL TESTS
}

Wayne E. Ferson

George M. Constantinides

Working Paper No. 3631

NATIONAL BUREAU OF ECONOMIC RESEARCH

1050 Massachusetts Avenue

Cambridge, MA 02138

February 1991

This paper is part of NBER's research program in Financial Markets and Monetary Economics. Any opinions expressed are those of the authors and not those of the National Bureau of Economic Research. 
NBER Working Paper \#3631

February 1991

\title{
HABIT PERSISTENCE AND DURABILITY \\ IN AGGREGATE CONSUMPTION : \\ EMPIRICAL TESTS
}

\begin{abstract}
Habit persistence in consumption preferences and durability of consumption goods are two hypotheses which imply time-nonseparability in the derived utility for consumption expenditures. We study a simple model with both effects, in which lagged consumption expenditures enter the Euler equation. Habit persistence implies that the coefficients on the lagged expenditures are negative, while durability implies positive coefficients. If both effects are present, then estimating the sign of the coefficients addresses the question as to which of the two effects is dominant. Earlier empirical work on monthly data supported the durability of consumption expenditures. We estimate and test the Euler equation using monthly, quarterly and annual data and find evidence that habit persistence dominates the effect of durability.

Wayne E. Ferson

Graduate School of Business

University of Chicago

1101 East 58th Street

Chicago, IL 60637

George M. Constantinides Graduate School of Business University of Chicago 1101 East 58th Street Chicago, IL 60637 and

National Bureau of Economic Research
\end{abstract}




\section{Introduction}

The consumption-based asset pricing model tested by Hansen and Singleton (1982, 1983), Ferson (1983), Grossman, Melino and Shiller (1987), Breeden, Gibbons and Litzenberger (1989) and others was derived under the assumptions that the utility function is time and state separable and that the consumption good is nondurable. Habit persistence in consumption preferences and durability of consumption goods both imply time nonseparability in the derived utility for consumption expenditures.

We illustrate the combined effects of durability in consumption expenditures and of habit persistence in preferences, using a simple theoretical model in which the durable good depreciates exponentially. Habit persistence is modelled by assuming that a consumer's subsistence level is a weighted sum of the past flows of consumption services. In this model, both current and lagged consumption expenditures enter the Euler equation. Habit persistence implies that the coefficients on the lagged expenditures are negative, while durability implies positive coefficients. If both effects are present, then the sign of the coefficients indicates which of the two effects is dominant.

In earlier work, Dunn and Singleton (1986), Eichenbaum, Hansen and Singleton (1988) and Elchenbaum and Hansen (1988) estimated a positive coefficient on lagged consumption in Euler equations for monthly data. They interpreted their results as evidence of durability in consumption expenditures. These studies used lagged consumption and returns as the predetermined information variables in the model.

We find that the results for monthly data are sensitive to the experimental design; in particular, to the choice of the instrumental 
variables. The evidence for durability is not robust. The signs of the coefficients on the lagged consumptions are no longer significantly positive, or they become negative when we experiment with different instrument sets. We argue that alternative instruments are preferable to those used in earlier studies and conclude that the effect of habit persistence dominates the effect of durability in monthly consumption expenditures.

We extend the investigation to quarterly and annual data and find evidence that habit persistence dominates durability at these frequencies as well. The evidence of habit persistence at the quarterly and annual frequencies is robust to the choice of instrumental variables. It is possible that durability of consumption expenditures has a sufficiently short half-life, in which case it is suppressed in the quarterly and annual data. Then habit persistence is more easily detected in the quarterly and annual data, provided that habit persists for longer than a quarter or year. In a calibration exercise to explain Mehra and Prescott's (1985) equity premium puzzle, Constantinides (1989) found evidence that habit persists for longer than a year.

Our results are reinforced by the recent work of Hansen and Jagannathan (1990) and Gallant, Hansen and Tauchen (1989), who study the moment inequality restrictions implied by the Euler equations. Winder and Palm (1989) estimate a IInearized form of the Euler equation and find support for habit persistence in the Netherlands. Heaton (1990) considers an explicit consumption process, assumes that the interest rate is constant and formally models the time-averaging of monthly and quarterly consumption data in a linearized version of the Euler equation. He finds evidence for short- 
lived durability in consumption expenditures and some evidence for habit persistence. Backus, Gregory and Telmer (1990) find that habit persistence helps to account for the variability of expected returns on currencies.

The paper is organized as follows. The model is stated and the Euler equation which incorporates nonseparable preferences and durability of consumption expenditures is derived in section 2 . The methodology is presented in section 3 . In section 4 we discuss the monthly, quarterly, and annual consumption expenditures data, the asset returns data and the predetermined instrumental variables. The main empirical results, presented in Tables 3-6 are discussed in section 5. The robustness of the empirical results is further examined in section 6 . In section 7 we reconsider the equity premium puzzle. In the concluding section 8 we offer suggestions for future work. An appendix illustrates the interpretation of the concavity parameter of the representative utility function under time-nonseparability. We argue that the parameter more closely approximates the risk aversion coefficient than the inverse of the intertemporal elasticity of substitution.

\section{The Model}

We consider a single-good economy in discrete time. Expenditures on the good at time $t$ by a representative consumer are denoted by $c_{t}$. The good is durable and durability is modelled as in Dunn and Singleton (1986), Eichenbaum, Hansen and Singleton (1988), and Eichenbaum and Hansen (1988). Each period the new expenditures $c_{t}$ produce a flow of consumption services $\delta_{r} c_{t}$ in period $t+r, T \geq 0$, where $\delta_{T} \geq 0$ and $\Sigma_{T-0}^{\infty} \delta_{T}-1$. The total flow of consumption services at time $t$ is given by 


$$
c_{t}^{F}-\sum_{T=0}^{\infty} \delta_{T} c_{t-T}
$$

The representative consumer's utility is defined over the flow of services $c_{t}^{F}$.

We model habit persistence with a time nonseparable von NeumannMorgenstern utility function

$$
(1-A) \sum_{t=0}^{-1} \beta^{t}\left(c_{t}^{F}-h \sum_{s=1}^{\infty} a_{s} c_{t-s}^{F}\right)^{1-A}
$$

where $A>0, a_{s} \geq 0, \sum_{s=1}^{\infty} a_{s}-1$ and $h \geq 0$. The time-preference parameter is a. The habit parameter $h$ represents the fraction of the weighted sum of lagged consumption flows which establishes a subsistence level of consumption. If $\mathrm{h}-0$ the utility function is time-separable in consumption flows (but not in consumption expenditures, unless $\delta_{T}-0, T \geq 1$ ).

Ryder and Heal (1973) studied the optimal consumption policy when the utility at time $t$ is defined as a concave function of the consumption flow at time $t$ and of a weighted sum of the lagged consumption flows. Sundaresan (1989) and Constantinides (1990) studied special cases in which the utility at time $t$ is a power of the difference between the consumption flow at time $t$ and a fraction of a weighted sum of lagged consumption flows, as in equation (2).

In the case of time separable preferences over consumption services (h 0) the concavity parameter $A$ is the relative risk aversion coefficient (RRA) and the inverse of the intertemporal elasticity of substitution. With habit persistence $(h>0)$ we show in the appendix that the parameter $A$ approximately equals the RRA coefficient but may differ substantially from the inverse of the intertemporal elasticity of substitution. 
We combine equations (1) and (2) and write the utility function as

$$
(1-A)^{-1} \sum_{t=0}^{\infty} \beta^{t} C_{t}^{1-A}
$$

where

$$
\begin{aligned}
c_{t} & =\sum_{\tau=0}^{\infty} \delta_{T} c_{t-\tau}-h \sum_{s=1}^{\infty} \sum_{\tau=0}^{\infty} a_{s} \delta_{T} c_{t-\tau-s} \\
& =\delta_{0} \sum_{\tau=0}^{\infty} b_{T} c_{t-\tau}
\end{aligned}
$$

and

$$
\begin{aligned}
& b_{0}-1 \\
& b_{r}=\left(\delta_{T} \cdot h \sum_{i=1}^{T} a_{i} \delta_{T-1}\right) / \delta_{0}, \quad T \geq 1 .
\end{aligned}
$$

It is instructive to consider an example with $\delta_{\tau}-(1-\delta) \delta^{T}$ and $a_{s}-(1-\alpha) \alpha^{s-1}$, where $0 \leq \delta<1$ and $0 \leq \alpha<1$. Then the coefficients b, become:

$$
b_{T}=\left[1-\frac{(1-\alpha) h}{\delta-\alpha}\right] \delta^{T}+\frac{(1-\alpha) h \alpha^{\top}}{\delta-\alpha}, \quad T \geq 1 .
$$

If expenditures are not durable $(\delta-0)$, we obtain $b_{T}--(1-\alpha) h^{T-1}$ and the coefficients are negative for $r \geq 1$. In the absence of habit persistence $(h-0)$ but with durability, we obtain $b_{r}-\delta^{T}$ and the coefficients are positive. When both habit persistence and durability are present, the coefficients $b_{r}$ are positive or negative depending on the relative magnitude of the durability parameter $\delta$ and the habit persistence parameters $h$ and $\alpha$. If $\delta \geq \alpha+h(1-\alpha)$. the coefficient $b_{r}$ is positive for all $r$; if $\delta \leq h(1-\alpha)$ then $b$, is negative for all $r \geq 1$; 
finally, if $h(1-\alpha)<\delta<\alpha+h(1-\alpha), b_{r}$ is positive for recent lags and negative for distant ones. The example illustrates the opposing role of habit persistence and durability on the coefficients of lagged consumption expenditures.

To derive the stochastic Euler equation in the general case, we consider a reduction of the representative consumer's expenditures in period $t$ from $c_{t}$ to $c_{t}-c$, where $|c|$ is small. The investment of $c$ in an asset with (stochastic) return $R_{t+1}$ over one period increases the consumption expenditures in period $t+1$ from $c_{t+1}$ to $c_{t+1}+c R_{t+1}$. The rational consumer takes into account the effect of the changes in consumption expenditures in periods $t$ and $t+1$ on the flow of consumption services and on the subsistence level in all future periods through equation (4) and calculates the change in $C_{t-\tau}, C_{t}$ and $C_{t+r}, \tau \geq 1$ as:

$$
\begin{aligned}
& \frac{\partial C_{t-r}}{\partial c}-0, r \geq 1 ; \\
& \frac{\partial C_{t}}{\partial c}-\delta_{0}, \\
& \frac{\partial C_{t+r}}{\partial c}=\left(b_{r-1} R_{t+1}-b_{r}\right) \delta_{0}, \quad r \geq 1 .
\end{aligned}
$$

Optimality requires that the expectation in period $t$ of the utility of the consumption flows is maximized at $c-0$, that is,

$$
\left.\frac{\partial}{\partial c}\right|_{c-0}\left[(1-A)^{-1} \sum_{r=-t}^{0} \beta^{t+\tau} C_{t+r}^{1-A}+E_{\tau}\left[(1-A)^{-1} \sum_{r-1}^{\infty} \beta^{t+r} C_{t+r}^{1-A}\right]\right]-0 .
$$

We combine equations (6) and (7), simplify and obtain the Euler equation

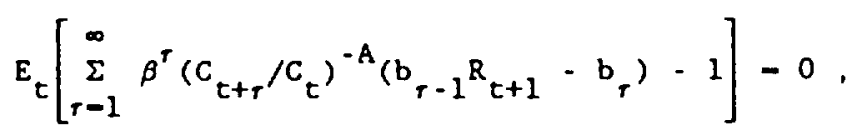

where $C_{t}$ is defined by equation (4). 
In the absence of habit persistence $(h-0)$ and durability $(\delta,-0$, $r \geq 1$ ) we obtain $b_{r}-0, r \geq 1$, and the Euler equation (8) becomes the time and state separable model examined by Hansen and Singleton (1982):

$$
E_{t}\left[\beta\left(c_{t+1} / c_{t}\right)^{-A} R_{t+1}-1\right]=0
$$

We consider a sequence of nested models of the Euler equation, starting with the time-separable model $\left(b_{r}-0, r \geq 1\right)$, and proceeding to a model with a one-lag specification $(b,-0, r \geq 2)$ and a model with a two-lag speciflcation $(b,-0, t \geq 3)$. Formally, the one-lag model captures habit persistence based on one lag in consumption, in the absence of durability; or it captures durability of one period only, in the absence of habit persistence. The two-lag model captures habit persistence based on two lags in consumption, in the absence of durability; or it captures durabllity of two periods, In the absence of habit persistence; or it captures habit persistence based on one lag in consumption and durability of one period.

\section{Methodology}

The Euler equation is tested and the model parameters are estimated using Hansen's (1982) Generalized Method of Moments (GMM). Equation (8) defines an error term $u_{1 t}$ for each asset $1,1-1, \ldots, N$, such that $E_{t}\left[u_{1(t+1)}\right]-0$, where $E_{t}[$.$] denotes the conditional expectation given information at t$ ime $t$. With a set of $L$ instruments, $z_{j t}, j-1, \ldots, L$, known to the market at time $t$, we obtain $E\left[u_{t+1} \mid z_{t}\right]-0$ and therefore $E\left[u_{t+1} z_{t}^{\prime}\right]-0$, where $u_{t+1}$ is the vector of $N$ error terms and $z_{t}$ is the vector of $L$ instruments. Given $N$ assets and $L$ instruments there are $N L$ orthogonality conditions. The GMM estimates are based on minimizing the quadratic form $g^{\prime} \mathrm{Wg}$ where $g$ is the 
NL vector of the elements of $(1 / T) \Sigma_{t} u_{t+1} z_{t}^{\prime}$ and $W$ is the inverse of a consistent estimate of the covariance matrix of these orthogonality conditions. Hansen (1982) discussed the weighting matrix $W$ and provided conditions under which the parameter estimates are consistent and asymptotically normal and the minimized value of the quadratic form is asymptotically chi-square under the null hypothesis. The model is overidentified provided that the number of orthogonality conditions, NL, exceeds the number of parameters. The minimized quadratic form provides a test statistic for the goodness-of-fit of the model; the number of degrees of freedom is the difference between the number of orthogonality conditions and the number of parameters. The parameters are $\beta, A,\left(b_{s}\right)$.

In the time-separable model $u_{t}$ is a function of the variables $R_{t}, c_{t-1}$, and $c_{t}$, which are known at time $t$. The Euler equation therefore implies that $E\left[u_{t+s} \mid u_{t}\right]-0, s \geq 1$, and we say that $u_{t}$ follows an MA(0) process. The time separable model implies the null hypothesis,

$$
H_{0}: b_{s}-0, s \geq 1 \text {, with an } \operatorname{MA}(0) \text { error term } u_{t} \text {. }
$$

In the one-lag model $\left(b_{s}-0, s \geq 2\right), u_{t}$ is a function of $R_{t}, c_{t-2}$, $c_{t-1}, c_{t}$ and $c_{t+1}$. Since $c_{t+1}$ is not in the time $t$ information set, the model does not imply that $E\left[u_{t+1} \mid u_{t}\right]-0$ but implies that $E\left[u_{t+s} \mid u_{t}\right]=0, s \geq 2$. We say that $u_{t}$ in this case follows an MA( 1$)$ process. In general, the model implies that the error term $u_{t}$ will be MA(q), where $q$ is the smallest number such that $b_{j}-0$ for all $j>q$. The one-lag model therefore implies the hypothesis, 


$$
H_{a}: b_{s}-0, s \geq 2 \text { with } M A(1) \text { error term } u_{t} \text {. }
$$

The autocorrelation of the error term under $\mathrm{H}_{\mathrm{a}}$ is related to the parameter $\mathrm{b}_{1}$ in a complex way. The weighting matrix is adjusted to account for the moving average terms, as described by Hansen (1982). When $b_{1}$ is zero, the model implies that the autocorrelation of the error becomes zero, hence the null hypothesis $\mathrm{H}_{0}$.

We model the consumer's decisions at fixed intervals, and we measure asset returns and consumption over the same intervals. Consumption decisions may actually occur more frequently. If the decisions are made within the observation interval and the measured consumption expenditures are the sum of the expenditures over the interval, then the consumption data are said to be time-aggregated. Formally modelling time-aggregation in the Euler equation is difficult and results for time-aggregation are only available in the literature, imposing a first-order approximation to the marginal utility function. We conduct several experiments to asses the likely importance of time-aggregation for our results. ${ }^{1}$

Using a linear approximation to the Euler equation, it can be shown that one effect of time-aggregation is to increase the order of the MA process followed by $u_{t} \cdot{ }^{2}$ Therefore, under time aggregation, the residuals may appear to behave like an $M A(1)$ process even if the nonseparability parameter $b_{1}$ is zero. Time-aggregation can also induce a spurious correlation between the error terms and the information set for time $t$. Therefore, variables in the market's information set at $t$ which were not in the market's information set at $t-1$ may not be valid instruments for the equation $E_{t}\left[u_{t+1}\right]-0$. 
Time aggregation is not the only feature of the aggregate consumption data which creates methodological problems. Other features of the data could induce autocorrelation in the error terms and spurious correlation between the error terms and the instruments. Examples include imperfect timing and interpolation of the consumption data, measurement errors and seasonal adjustment. A rejection of $\mathrm{H}_{0}$ could be interpreted as evidence that these other features of the data are important, rather than evidence that $b_{1}$ is not zero. We therefore examine the modified null hypothesis,

$$
H_{0}^{\prime}: b_{1}-0 \text {, with an MA(1) error term } u_{t} \text {. }
$$

against the alternative hypothesis $H_{a}$. We further asses the sensitivity of our results to these data issues by conducting experiments in which the order of the MA process of the errors is varied and in which the instruments for the information set at time $t$ either admit or do not admit the most recent lagged values of the variables.

The parameter estimates and statistical tests using the GMM are justified from asymptotic distribution theory. There is a natural concern about the properties of these procedures in small samples. Tauchen (1986) and Kocherlakota (1990) provided simulation evidence for the time-separable model. Tauchen found that the test statistics perform well with as few as 50 annual observations, although he found a slight tendency to reject the model too infrequently. Kocherlakota (1990), using a different set of parameter values, found cases where the model is rejected too often. When the tests exploit only unconditional moment restrictions, i.e., when the instrument is a constant vector of ones (a case we examine below), he found that the test 
statistics perform well in small samples. Both of these studies found that the coefficient estimates and their standard errors can be unreliable in small samples.

Although we report the coefficient estimates and their asymptotic standard errors, we stress that the reliability of these estimates cannot be assessed until simulation studies of the finite sample properties of the GM become avallable for nonseparable consumption models. We therefore refrain from deriving detailed implications from the models which depend on the point estimates of the coefficients.

Ferson and Foerster (1990) studied the finite sample properties of the GMM in a linear asset pricing context with cross-equation restrictions. They found that a two-stage GMM approach, as described in Hansen and Singleton (1982), tends to reject the model too often in larger systems, while an iterated GMM approach provides more accurate test statistics. We use an iterated GM approach in this study. 3

\section{The Data}

We study the returns of Treasury b1lls, bonds and value-weighted portfolios of common stocks traded on the New York Stock Exchange (NYSE). The stocks are grouped into size deciles, based on the market value of equity outstanding at the beginning of each year. We examine a subset of the 10 deciles: deciles 1,5, and 10. Declle 1 represents the common stocks of small flrms, and declle 10 represents large firms. Three portfolios are chosen to keep the number small, while capturing most of the stock return behavior that would be reflected in a design using all ten deciles or using value - and 
equally-weighted stock indices. We include a long-term government bond return and the return to a strategy of rolling over one-month Treasury bills. Thus, a total of 5 portfolio returns are examined. All of the asset return data are from the Center for Research in Security Prices of the University of Chicago (CRSP).

Our primary measure of consumption is real, per capita expenditures on consumer nondurable goods. These data are seasonally adjusted by the Commerce Department, using the $X-11$ seasonal adjustment program. The quarterly data are in real terms, as reported by Data Resources Inc. (DRI). The annual consumption data are from the Commerce Department's Business Statistics, 1959 edition, and DRI. ${ }^{4}$ Monthly data are obtained from Citibase. The real expenditure totals are divided by the population to obtain the per capita real consumption series. The population figure is the total United States residential population (excluding armed forces abroad) from statistical Abstract of the U.S., DRI, and Citibase.

We examine data for durable goods expenditures and for seasonally unadjusted consumption in some experiments. The seasonally unadjusted data are the quarterly nominal expenditures from DRI, divided by the population and deflated by a seasonally unadjusted component of the consumer price index (CPI). ${ }^{5}$

The real asset returns are the nominal returns deflated by the price deflator for the measure of consumption in a given model. For example, when we use nondurable goods expenditure data we deflate the asset returns by the deflator for consumer nondurable goods. When we use the seasonally unadjusted consumer durables expenditure data, we deflate the returns by the seasonally unadjusted consumer price index for consumer durables. 
The earlier studies of Dunn and Singleton (1986), Eichenbaum, Hansen and Singleton (1988) and Eichenbaum and Hansen (1988) used monthly consumption data to explore time-nonseparable models. We focus mostly on the quarterly and annual data. Monthly consumption data are suspect for at least two reasons. First, measurement error which can induce negative serial autocorrelation in consumption growth, is likely to be proportionately more important in monthly data. Second, components of the monthly consumption expenditures are calculated by interpolation, which may induce positive serial autocorrelation. Durability of consumption expenditures induces negative autocorrelation in consumption growth. For example, a consumer purchasing an automobile in one period is likely to refrain from purchasing another automobile for several periods. Habit persistence induces positive autocorrelation in consumption growth since the consumer maximizes utility by smoothing consumption more than would be optimal with time-separable preferences. Therefore, spurious positive (negative) autocorrelation in consumption growth may lead to the erroneous conclusion that durability of consumption expenditures dominates (is dominated by) habit persistence.

Previous studies of consumption-based models have used lagged values of consumption and returns as instruments to estimate the parameters and test the Euler equation. However, as discussed above, measurement errors and other data problems can result in spurious correlation between the consumption and real returns and their lagged values. The spurious correlation can lead to spurious rejections of the Euler equations and can bias the parameter estimates. We use lagged consumption and returns in some experiments for comparison purposes, and to. check the sensitivity of our results. However, we focus mostly on instruments that are distinct from the lagged 
values, but which can predict both asset returns and measures of consumption growth. Such instruments should provide powerful tests of the Euler equation restrictions. The instrumental variables are summarized in Figure 1.

insert figure 1 here

VrYLD (-1) is the average dividend yield on a value-weighted index of common stocks traded on the New York stock exchange, provided by CRSP. The dividend yield is the sum of the most recent year's dividends divided by the price level on the last trading day of the quarter. The symbol $(-1)$ indicates that a variable is lagged one period relative to the date of the asset return realization in the Euler equation. For example, the dividend yield used to predict returns for the first quarter uses the price level at the end of the previous December and dividends over the previous year. Using the annual dividends avoids the seasonality of dividend payments. Dividend yields are a component of the return of stocks, so the ex-ante dividend yield is a natural instrument for capturing variation in expected stock returns. Campbell and Shiller (1988), Cutler, Poterba and Summers (1988), Fama and French (1988), and others found that dividend yields predict future stock and bond returns. The symbol (-2) indicates that a variable is lagged two periods.

DIVDIFF(-1) is the dividend yield of the CRSP equally-weighted stock index less the dividend yield of the value-weighted stock index. Movements in this variable over time reflect the differences between the dividend yields of small and large firms. We find that the difference contributes additional explanatory power, given the level of the yield, in regressions for the future returns and consumption measures. 
TB1MO(-1) is the nominal, one-month Treasury bill rate. The abllity of short-term bills to predict monthly returns of bonds and stocks is documented by Fama and Schwert (1977) and others.

$\mathrm{Pl}(-1)$ is a measure of the detrended price level for the smallest decile of common stocks. This is the inverse of the price index level, relative to the average level over the preceding twelve months. Keim and Stambaugh (1986) studied a similar variable and found that it predicts both bond and stock returns. This variable may capture the reversion of expected returns to their long-run means. Mean reversion implies that if stock returns are below average (so that prices are relatively low), then conditional expected returns are higher than average.

GIPX (-1) is the continuously-compounded annual growth rate of an index of U.S. industrial production, lagged one quarter.

SSLOPE $(-1)$ is the three-month Treasury b111 rate, less the one-month return of a one-month bill. This is one of three instruments which decompose risky debt yields into short-term and long-term default-free slope variables, and an ex ante default premium for corporate debt. Fama (1984), Campbell (1987), and Stambaugh (1988) found that short term measures of the term structure can predict bond returns of different maturities and stock returns. LSLOPE (-1) is the long-term slope, measured as the lagged value of the yield-to-maturity of Aaa corporate bonds, less the one-month Treasury bill rate.

CBPREM(-1) is the lagged value of the average monthly yield-to-maturity of corporate bonds rated Baa by Moody's Investor Services, less the lagged value of the Aaa corporate bond yield. Keim and Stambaugh (1986) found that a yield spread has predictive power for bond and stock returns. 
The predetermined variables follow empirical studies which document their ability to predict the returns of portfolios similar to the ones we study. Statistical inference is complicated if the varlables are the result of collectlve "data snooping" by a series of researchers. We do not attempt to formally account for these effects in our analysis. 6

Tables 1 and 2 present sumary statistics for the basic data. The sample pertod of the quarterly analysis is 1948-1986; the annual data are for 1929 1986; monthly data cover 1959-1986. For annual data we use a subset of the instrumental variables. These are VWYL, DIVDIFF, TB1MO, P1 and SSLOPE. Table 1 shows that some of the autocorrelations of the instruments are above 0.9 (the quarterly CBPREM, VWYLD, DIVDIFF and TBIMO, and also GIPX in monthly data). In the case of VWYLD AND DIVDIFF, this is expected given the overlapping nature of the numerators. GIPX is an annual growth rate. The autocorrelations decay toward zero at longer lags for all of the variables. Table 2 shows the contemporaneous correlations among the instruments. The correlations suggest that none of the instruments are redundant and that multicollinearity should not be a problem. Only three (two) of the correlations among the quarterly (annual) instruments exceed 0.5 , and the largest is $0.67(0.69)$. In monthly data, five of the correlations exceed 0.5 and the largest is 0.74 .

insert tables 1 and 2 here

We examine time-series regressions, using the instruments to predict the future returns of the common stock and bond portfollos and the future growth rates of consumption. The asset returns are measured in excess of the three- 
month Treasury bill return. ${ }^{7}$ These regressions suggest that the instruments should allow us to construct powerful tests of the Euler equation. The signs and magnitudes of the coefficients on the asset returns are consistent with earlier studies. For example, $\operatorname{VWr} L(-1)$ enters with a positive coefficient and TBIMO enters with a negative coefficient in each of the regressions. The R-squares (right-tail probability values) for the quarterly sample range from $0.12(0.02)$ to $0.26(0.00)$ across the portfolio returns. In annual regressions, the range is from $0.12(0.29)$ to $0.48(0.00)$. In monthly data, the range is from $0.06(0.01)$ to $0.11(0.00)$. The instruments seem to capture changing expected excess returns in both the bond and stock markets. The instruments are less strongly related to the growth rates of future consumption expenditures. The R-squares in regressions predicting the growth of nondurables consumption expenditures are $0.09,0.12$, and 0.02 . respectively, in quarterly, annual and monthly data. The corresponding righttail probability values are $0.09,0.29$, and 0.66 , respectively.

\section{Empirical Results}

In Tables 3-6 we present the results of estimating and testing the models using monthly, quarterly and annual consumption expenditures and returns data. Since earlier work focussed on monthly data we examine first the monthly data. We use five assets: the three common stock portfollos from size deciles 1,5 and 10; a long-term government bond portfolio; and a onemonth Treasury bill. 
In the first panel of Table 3 we present results using seven instruments: a constant and three variables lagged once and twice relative to the date of the realization of the five asset returns. The three variables used as instruments are the real consumption growth over one month, the real return of a one-month Treasury bill and the real one-month return of the small stock portfolio. The errors $u_{t+1}$ in the Euler equation $E_{t}\left[u_{t+1}\right]-0$ are assumed to follow an MA(O) process in the time separable model and an MA( 1 ) process in the one-lag model.

In the first row of Table 3 the notation $b_{1}=0$ states that the nonseparability parameter is set equal to zero and we are then estimating and testing the time separable model. The point estimate of the subjective discount rate in this case is .993 and the estimate of the concavity parameter $A$ is 0.31 . However, the right tail p-value for the goodness-of-fit test is .006 and the model is rejected. Rejecting this model is consistent with the earlier conclusions of Hansen and Singleton (1982) and others.

In the second row of Table 3 the nonseparability parameter $b_{1}$ is unrestricted and is estimated along with the parameters $\beta$ and $A .{ }^{8}$ The model is not rejected by the goodness-of-fit test, the p-value being .15 . The subjective discount rate is very close to one and the concavity parameter is $A-2.1$. As we argue in the Appendix, in the nonseparable model the concavity parameter is approximately equal to the RRA coefficient but may differ substantially from the inverse of the intertemporal elasticity of substitution in consumption. The point estimate of the nonseparability parameter $b_{1}$ is positive and significantly different from zero. Taking the result at face value, it provides evidence that durability of consumption expenditures dominates the effect of habit persistence in a one-lag model. 
consistent with the earlier findings of Dunn and Singleton (1986), Elchenbaum, Hansen and Singleton (1988) and Elchenbaum and Hansen (1990). However, this result is not robust.

In the lower portion of panel 1, Table 3, we replace the lagged consumption and return instruments by a constant and the lagged financial variables summarized in figure 1. The point estimate of $b_{1}$ is now -0.72 and is significantly different from zero. The p-value of the goodness-of-fit test is high, .347 . These numbers suggest that the effect of habit persistence dominates the effect of durability of consumption expenditures.

These results serve two purposes. First, they demonstrate that we can replicate earlier results using our data sample. Second, they provide a warning that the estimation of the nonseparability parameter is potentially sensitive to the choice of instruments.

In panel 2 of Table 3 we exclude the first lagged values of the variables from the set of instruments, using only the second lagged values. This experiment can be motivated by concerns about measurement errors in the data, publication $\mathrm{lag}$ or by time aggregation. In the first subpanel with consumption and returns as instruments the point estimate of $b_{1}$ is .065 and the standard error is .227 , providing no evidence that either habit persistence or durabillty plays a dominant role. Moreover, the tests do not reject the time-separable model. In the lower part of panel 2 , using the second lags of the financial variables as instruments, we estimate a negative value of $b_{1}$ which is nearly three standard errors from zero. The timeseparable model is strongly rejected by the goodness-of-fit test.

In panel 3 of Table 3 we repeat the experiment of panel 2, except that we increase the order of the moving average process that is assumed for the 
error terms. In the time-separable model $\left(b_{1}-0\right)$ we use an $M A(1)$ assumption and in the one-lag model we use an MA(2). The results are comparable to those of panel 2. When lagged consumption and returns are the instruments the estimate of $b_{1}$ is close to zero and the time-separable model is not rejected. When the lagged financial variables are the instruments the time-separable model is rejected. The point estimate of $b_{1}$ is negative and the timenonseparable model is not rejected.

We conclude from Table 3 that the evidence of durability in the monthly consumption expenditures relies on using the most recent lagged values of the endogenous variables as instruments. However, there are reasons to be suspicious of results that rely on these instruments. The first lagged values of consumption and returns are suspect, given the potential problems with measurement errors, publication lag and time aggregation. In contrast, whether we use the first or the second lags of the financial variables as instruments, we estimate negative $b_{1}$ coefficients, which suggests that habit persistence dominates the effects of durability. Of course, given the problems with monthly consumption data, evidence based on the monthly data is not conclusive.

In Tables 4 and 5 we present results using quarterly and annual consumption expenditures and returns. We use as instruments either the financial variables lagged by one period, the financial variables lagged by two periods or the consumption and return variables lagged by one and two periods. Tables 4 and 5 sumarize the results for the one-lag model. Table 4 presents quarterly data, assuming that decisions are made quarterly. In Table 5 we assume an annual decision interval and use annual data. 
In Table 4, the results for quarterly data use two systems of asset returns. The first system is simflar to the monthly, five-asset system and consists of the three size portfollos of stocks (deciles 1, 5 and 10), a portfolio of long-term government bonds and a strategy of rolling over onemonth Treasury bills. In this system of asset returns the model is challenged to explain the differences in the returns of comron stocks grouped by firm size, which have served as an acid test of the Capital Asset Pricing Model. The second system consisting of just two assets, the Treasury bills and the large stocks, directs attention to the differences in the return of Treasury bills and stocks.

In panel 1 of Table 4 the instruments are a constant and the elght financial variables lagged once relative to the date of the realization of the asset returns. In panel 2 the financial instruments at lag two are used. The point estimates of the parameter $b_{1}$ all 1 ie between -.95 and -.97 and they are many standard errors away from zero. The goodness-of-fit tests indicate a markedly improved fit when the nonseparability parameter is included. The results suggest that the effects of habit persistence dominate the effects of durability in the quarterly data. 9

In the monthly data evidence of durability in consumption expenditures emerged only when the first lagged values of the consumption and returns were used as instruments. In panel 3 of Table 4 we replicate this experiment with quarterly data. The results show that, merely by switching from monthly to quarterly data, the evidence in favor of durability of consumption 
expenditures disappears. For the five-asset system the coefficient $b_{1}$ is negative and statistically different from zero and for the two-asset system the point estimate of $b_{1}$ is negative but insignificantly different from zero.

In Table 5 we repeat the tests reported in Table 4 with annual rather than quarterly data. These results provide further evidence that the effects of habit persistence dominate the effects of durability. All of the point estimates of $b_{1}$ are negative and the goodness-of-fit test results are improved. The annual data, of course cover a longer sample period and may be less influenced by measurement errors. Furthermore, results using the annual data should not be affected by problems with the seasonality of consumption expenditures and returns within the year. 10

These results may be understood in terms of the time series properties of consumption and the predictive ability of the different instruments for asset returns and consumption. In monthly data, consumption growth rates are negatively autocorrelated. In quarterly data the autocorrelation is closer to zero and in annual data the autocorrelation is positive (see Table 1). Positive autocorrelation in consumption combines with a negative nonseparability parameter to raise the volatility of the intertemporal marginal rate of substitution. This is one dimension along which habit persistence improves the fit of the model in quarterly and annual data. Negative autocorrelation in consumption combines with a positive nonseparability parameter in a simflar way, which suggests durability. Using lagged consumption and returns as the instruments, the autocorrelation properties of consumption are given more weight in the Euler restrictions. Therefore, when we use monthly consumption data and lagged consumption 
instruments, we find evidence for durability in monthly data.

When the lagged financial instruments are used in the Euler equation, the predictive power is relatively higher for the asset returns, and lower for the future consumption, than when lagged consumption growth rates and returns are used as the instruments. Habit persistence tends to reduce the intertemporal elasticity of substitution, which suggests relatively higher volatility in expected returns relative to consumption changes. These effects receive more weight in the Euler restrictions when the lagged financial variables are the instruments. We therefore find evidence for habit persistence, even in the monthly data, when the lagged financial variables are used.

insert figure 2 here

Figure 2 illustrates the sensitivity of the one-lag model to the value of the nonseparability parameter $b_{1}$. The values of the objective function are plotted, minimized over the choice of $A$ and $\beta$, for given values of $b_{1}$. An MA(1) weighting matrix is used. Results for annual data and five assets are plotted. (Similar patterns are observed in the other cases.) The objective function is highly nonlinear in the parameter $b_{1}$. Typically, we find that there is a local minimum in the region of durabllity $\left(b_{1}>0\right)$, and there is a "hill" in the objective function over which the algorithm must climb to attain the global minimum in the habit persistence region $\left(b_{1}<0\right)$.

Table 6 reports tests of the hypothesis $H_{0}^{\prime}$, that the parameter $b_{1}$ is zero, allowing the error term to be $M A(1)$, against the alternative that $b_{1}$ is not zero. Two test statistics are reported. The two statistics have the same 
asymptotic distribution under the null hypothesis, $H_{0}^{\prime}$. One statistic is the square of the t-ratio for the $b_{1}$ parameter. The second test uses the approach described in Eichenbaum, Hansen and Singleton (1988). The restricted system (imposing $b_{1}-0$ ) is estimated using the GMM weighing matrix from the unrestricted system, allowing the MA(l) error structure. The difference between quadratic forms using the restricted and the unrestricted objective function is asymptotically distributed as a chi-square variate with one degree of freedom.

Insert table 6 here

Table 6 shows that the two statistics imply the same inferences, so there is no signal of departures from the large-sample properties of the statistics. The tests reject the null hypothesis $H_{0}$ against $H_{a}$ in three of four cases. In the fourth case, the two asset system with annual data, neither test can reject the null hypothesis. Overall, a negative value of the nonseparability parameter is supported by the evidence.

insert figure 3 here

We find that direct estimation of the two-lag nonseparable model is problematic. It is difficult to estimate both $b_{1}$ and $b_{2}$ with precision. Figure 3 illustrates the problem. We establish a grid of values for $b_{1}$ and $b_{2}$, in increments of 0.1 . At each point in the grid we condition on these values and we search for $A$ and $\beta$ to minimize the objective function. Figure 3 shows the right-tail probability value associated with the minimized value of 
the objective function on the vertical axis, plotted against the specifled values of $\left(-b_{1}\right)$ on the $x$-axis and $\left(-b_{2}\right)$ on the rellef axis. The figure therefore provides a representation of the goodness-of-fit of the model for particular values of the nonseparability parameters. An MA(2) weighting matrix is used for every point on the grid. Results for the five-asset system and quarterly data are shown. A point in the center of the $x$-relief plane corresponds to the time-separable model $\left(b_{1}-0, b_{2}-0\right)$. Moving toward the $r i g h t$ rear corner implies increasing durability and moving toward the left front corner implies habit persistence. There is a "ridge," along which $b_{1}$ and $b_{2}$ add up to about -0.90 , in the habit persistence region of the figure. The value of the objective function is insensitive to the individual coefficients $b_{1}$ and $b_{2}$. Therefore, the individual coefficients cannot be estimated reliably. We found a similar result when we estimated the two-lag model with annual data. Although our results suggest that habit persistence is empirically relevant, the two coefficients cannot be estimated reliably. Therefore, we cannot infer the half-life of habit persistence. 11

\section{The Robustness of the Empirical Results}

\subsection{Seasonal Adjustment of Consumption}

The estimates and test results reported in Tables 3-6 are based on seasonally-adjusted data, as explained in section 4. The nonseparable models Imply that the flow of services and the subsistence level are averages of lagged consumption expenditures. But seasonally-adjusted consumption data have already been smoothed with the $X-11$ seasonal adjustment program. The smoothing by $x-11$ could bias the tests and the estimates of the parameters. 
The similarity of our findings using quarterly and annual data suggests that the results are not driven by seasonality or by the particular seasonal adjustment employed within the year. An appealing way to further verify that the results are not sensitive to seasonal adjustment is to use unadjusted quarterly expenditures data and to allow for seasonal variation in the utility function as in Miron (1986), Ferson and Harvey (1990) and English, Miron and Wilcox (1989). These studies introduced multiplicative "taste shift" parameters which allowed the utility for a given level of consumption to vary with the season. We attempted in some experiments to incorporate seasonal taste shift parameters together with the nonseparability parameter $b_{1}$ in the model. We were unable to reliably estimate a model with the additional parameters.

We report the results of a simple experiment which is less ambitious than the above. We adopt a two-step approach. In the first step, we regress the logarithm of unadjusted, quarterly real per capita consumption expenditures on a time trend and dummy variables indicating the quarter. We take the residuals from these regressions, add back the sample means and exponentiate. The resulting consumption series is seasonally adjusted, but avoids the moving averages used by $X-11.12$ The procedure is similar to assuming multiplicative seasonal taste shock parameters, as in Miron (1986). In the second step, we use the dummy-adjusted data to estimate and test the Euler equations (8) and (9). In principle, one would like to combine the two steps; but the two-step approach does provide some indication of the potential sensitivity of our findings to the method of seasonal adjustment. ${ }^{13}$ 
insert table 7 here

The results are summarized in Table 7 and are similar to Table 4 . The goodness of fit statistics imply that habit persistence improves the fit of the model. The point estimates of the nonseparability parameter $b_{1}$ are negative and they are several standard errors from zero.

\subsection{Expenditures on Durable Goods}

The Commerce Department provides data on three groups of consumer expenditures, which are labelled as durables, nondurables and services. Our estimates and tests reported in sections 5 and 6.1 used the nondurables series, excluding the durables and services. We recognized that the Commerce department's nondurables series may in fact be durable, and we accounted for the durability in the derivation of the nonseparable models. Our approach is formally justified under the assumption that the consumer's preferences are separable over the flow of services from the Commerce department's durables, nondurables and services.

Dunn and Singleton (1986), Eichenbaum, Hansen and Singleton (1988), and Eichenbaum and Hansen (1990) derived, estimated and tested Euler equations for models with nonseparable preferences across goods. The degree of substitution across the goods is parameterized. If we allow for such preferences, which are both time-nonseparable and nonseparable across goods, the number of parameters in the model becomes large.

insert table 8 here 
In this section we adopt the maintained hypothesis that the preferences are separable across goods and focus on the Euler equation implied by timenonseparable preferences, defined over the flow of services from the Commerce department's durable goods expenditure series. Results for annual and quarterly data (both $\mathrm{X}-11$ and dummy adjusted versions) are reported in Table 8. One might expect $b_{1}$ to be positive for consumer durables, but the point estimates of $b_{1}$ - although greater than the point estimates for nondurables - are less than zero in all six cases. The goodness-of-fit tests indicate an improved fit with the negative $b_{1}$ coefficients. We conclude that our earlier finding that habit persistence dominates durability is not due to the fact that we excluded the consumption flows from the durable goods expenditure series.

Figure 4 illustrates the sensitivity of the objective function to the value of the nonseparability parameter $b_{1}$, using durable goods expenditures. The values of the objective function, minimized over the choice of $A$ and $\beta$, are plotted for fixed values of $b_{1}$. Results for quarterly (X-11 adjusted) data and all five assets are plotted. Similar patterns are observed in the other cases, and the conclusion is similar to that obtained from figure 2. Typically, however, a local minimum in the region of durability is closer to the global minimum in the region of habit persistence, when durable goods expenditures are used than when nondurables are used.

insert figure 4 here

Since the results for nondurable and durable goods are similar, it is unlikely that the sum of the two would lead to different conclusions. 
However, there are potential difficulties in the interpretation of the experiments in Table 8 and Figure 4. If preferences are not separable across durable and nondurable goods, then applying the model to data on durable goods creates a missing variables problem. Because nondurables and durable goods expenditures are correlated, the durable goods expenditures may proxy for the missing nondurables expenditures. The estimates of the nonseparability parameter may thus be blased toward hablt persistence. A multigood model could potentially control for this effect, although the larger number of parameters will create econometric difficulties. We leave for future research a complete study of the interaction between habit persistence and the complementarity or substitutability of different consumption goods.

\section{The Equity Premium Revisited}

Mehra and Prescott (1985) introduced the equity premium puzzle. They considered a pure exchange economy in which the representative consumer has time- and state-separable preferences with constant RRA coefficient. They assumed that consumption growth is a two-state Markov process and calibrated this process to match the sample mean, variance and first-order autocorrelation of the annual growth rate of per capita consumption in the years 1889-1978. They were unable to find a plausible pair of the subjective discount rate and the RRA coefficient to match the sample mean of the annual real rate of interest and of the equity (stock market) return over the same 90-year perlod.

The calibration exercise of Mehra and Prescott is not directly comparable 
to the estimation and testing of Euler equations which we reported in the earlier sections. Our starting point was a system of Euler equations:

$$
E_{t}\left[R_{L(t+1)} M R S_{t+1}\right]=1 \text {, }
$$

where $R_{1(t+1)}$ is the one-plus-return on asset 1 over $[t, t+1]$ and MRS $_{t+1}$ is the marginal rate of substitution between dates $t$ and $t+1$. The Euler restrictions that we tested Included in particular the unconditional Euler equation:

$$
E\left[R_{1(t+1)} M R S_{t+1}\right]=1
$$

Using predetermined variables $z_{j t}$ as instruments, we included additional implications of the Euler equation, specifically:

$$
E\left[R_{1(t+1)} \operatorname{MRS}_{t+1} \mid z_{j t}\right]-1 \text {. }
$$

Including the predetermined instruments, our estimates of the RRA coefficient were reasonable in magnitude, for both the time separable and the nonseparable models. In contrast. Mehra and Prescott found that a large RRA coefflcient is implied by the mean equity premium.

\section{insert table 9 here}

Hansen and Singleton (1983) and Ferson and Harvey (1990) observed that when the Euler equation with $b_{1}-0$ is estimated using only unconditional moments, large but imprecise estimates of the risk aversion coefficient are found. In Table 9 we repeat the tests of Tables $4,5,7$ and 8 using a constant as the only instrument. The five-asset system is examined, because the two-asset systems are not overidentified. The estimates of the concavity 
parameter A are typically larger than in the previous tables. Using nondurable goods the estimates of $b_{1}$ are negative in two of the three experiments, which suggests habit persistence. Using durable goods expenditures all three point estimates are positive, which suggests durability in expenditures. However, none of the estimates in Table 9 are precise and the goodness of fit statistics do not indicate an improved fit when we allow for nonseparable preferences. 14

In what sense then, does habit persistence explain the equity premium puzzle, as claimed in Constantinides (1989)? To provide an answer to this question, consider adding a mean preserving spread ${ }^{e} t+1$ to the asset return $R_{i(t+1)}$ as $R_{i(t+1)}+e_{t+1}$, where $E_{t}\left[e_{t+1}\right]-0$ and $E_{t}\left[e_{t+1} M s_{t+1}\right]-0$. If equation (10) holds, so does the equation

$$
E_{t}\left[\left(R_{i(t+1)}+e_{t+1}\right) M R S_{t+1}\right]-1 \text {. }
$$

This implies that conditional and unconditional tests of the Euler equation do not focus on the variance of asset returns. Likewise, matching the variance of the equity premium was not one of the goals addressed by Mehra and Prescott (1985).

By contrast, Constantinides' (1990) goal was to match both the mean and the variance of the equity premium. He demonstrated that habit persistence improves upon time separable preferences. The mean equity premium is driven by the RRA coefficient rather than the elasticity of substitution in consumption. As we demonstrate in the Appendix, habit persistence has a second-order effect on the RRA coefficient and, predictably, does not improve significantly on the mean equity premium. The variance of the equity premium is driven by the elasticity of substitution in consumption. As we 
demonstrate in the Appendix, habit persistence decreases substantially the elasticity of substitution and implies that a small variance of consumption growth is associated with a large variance of the equity premium.

In Table 10 we provide additional evidence on this issue. We repeat the tests of Table 4, but we replace the real return of the Treasury bill in the Euler equation with the real return plus a parameter L. This parameter allows the unconditional mean return of the bill, and therefore the mean excess return or premium of an asset relative to the bill, to be unrestricted. Any rejection of this model will not be driven by an inability to fit the mean bill return. The $L$ parameter can be interpreted as a pricing error, similar to a "Jensen's alpha" In the Capital Asset Pricing Model, or as a liquidity premium on the bill return that is not captured by the model.

Table 10 shows that the point estimates of $L$ are positive and, in the twoasset system, are significantly different from zero. This implies that the average bill return which best fits the model is higher than the historical average return, consistent with the pattern In Mehra and Prescott (1985). But the goodness-of-fit tests and the estimates of $b_{1}$ do not change much from the results in Table 4. Thus, the tests are not highly sensitive to the average level of the interest rate. This supports the interpretation that habit persistence improves the fit of the model largely through its effect on moments other than the mean equity premium. 15 


\section{Suggestions for Future Research}

Our study suggests several avenues for future research. One extension is a multiple-good model, which may provide further evidence on substitution across consumption goods in the presence of habit persistence and durability. Such a model could potentially identify the separate effects, but our results suggest that more complex specifications will be econometrically challenging. Further work is required to better understand the relation of seasonality and habit persistence. Another challenge is to model several frequencies of consumption and asset holding perlod returns simultaneously. Such an approach is potentially promising, given the different time-series properties of asset returns and consumption over different holding periods and given our evidence which suggests nonseparabilities that operate at different frequencies. 


\section{APPENDIX}

With habit persistence and/or durability the RRA coefficient and the intertemporal elasticity of substitution depend on the parameters of the probability distribution of the asset returns. With plausible assumptions on the parameters of the probability distribution, Constantinides (1990) proved that the RRA coefficient approximately equals the parameter $A$ and that the intertemporal elasticity of substitution in consumption can be substantially lower than the inverse of the relative risk aversion coefficient. These insights are important in the interpretation of our empirical findings and are illustrated here in the context of a simple deterministic economy.

We assume that the investment opportunity set consists of just one asset which is riskless and has (one plus) rate of return $R$ each period. The representative consumer's preferences are the special case of the preferences represented by equations (3)-(4) with $\delta_{0}-1, b_{1}--h$ and $b_{r}-0$ for $r \geq$ 2. The preferences then become

$$
(1-A)^{-1} \sum_{t=0}^{\infty} \beta^{t}\left(c_{t}-h c_{t-1}\right)^{1-A} \text {. }
$$

The consumer's initial endowment is $W_{0}$. The consumer receives zero endowment or labor income. Therefore the equation of motion of wealth, in units of the consumption good, is

$$
w_{t}-\left(w_{t-1}-c_{t-1}\right) R
$$

An admissible consumption plan is defined by the properties $0 \leq c_{t}<\infty$,

$$
\begin{gathered}
0 \leq c_{t}-h c_{t-1} \text { and } 0 \leq w_{t} \text { for all } t \text {. The conditions } \\
w_{0}-\frac{h R c_{-1}}{R-h} \geq 0
\end{gathered}
$$


and

$$
\mathrm{R}>\mathrm{h}
$$

guarantee that the set of admissible plans is non-empty. For example, the consumption plan $c_{t}-h^{t+1} c_{-1}$ is feasible because it implies $c_{t}>0, c_{t}$ $h c_{t-1}-0$ and has a discounted present value $\sum_{t-0}^{\infty} R^{-t_{h} t+1} c_{-1}-h R c_{-1} /(R-h)$ which is less than or equal to $W_{0}$, by the condition (A.3). Finally, the right-hand part of the inequality

$$
1<(\beta \mathrm{R})^{1 / A}<\mathrm{R}
$$

guarantees that the utility of consumption over the infinite horizon is finite under all feasible consumption plans.

Define the derived utility of wealth at time $t$ by the recursive equation $V\left(W_{t}, c_{t-1}\right)=\max _{c_{t}}\left[(1-A)^{-1}\left(c_{t}-h c_{t-1}\right)^{1-A}+\beta V\left(\left(W_{t}-c_{t}\right) R, c_{t}\right)\right]$.

The first order condition with respect to $c_{t}$ is

$\left(c_{t}-h c_{t-1}\right)^{-A}-\beta R V_{1}\left(\left(W_{t}-c_{t}\right) R, c_{t}\right)+\beta V_{2}\left(\left(W_{t}-c_{t}\right) R, c_{t}\right)-0$

where $v_{1}$ and $v_{2}$ are the derivatives of $v$ with respect to its first and second arguments, respectively. The solution of equations (A.6) and (A.7)

gives the optimal consumption plan as

$$
c_{t}-\left(R-(\beta R)^{1 / A}\right)(R-h) R^{-2} W_{t}+(\beta R)^{1 / A} h R^{-1} c_{t-1}
$$

and the derived utility of wealth as

$$
V\left(W_{t}, c_{t-1}\right)-\frac{K}{I-A}\left(W_{t}-\frac{h R c_{t-1}}{R-h}\right)^{1-A}
$$


where

$$
K=\left(R-(\beta R)^{1 / A}\right)^{-A}(R-h)^{1-A} R^{2 A-1}
$$

We proceed to derive the time series of consumption. Equation (A.8) gives $W_{t}$ in terms of $c_{t}$ and $c_{t-1} ;$ and the one-lag version of (A.8) gives $W_{t-1}$ in terms of $c_{t-1}$ and $c_{t-2}$. We eliminate $w_{t}$ and $w_{t-1}$ from equation (A.2) and obtain

$$
c_{t}=\left((\beta R)^{1 / A}+h\right) c_{t-1}-h(\beta R)^{1 / A} c_{t-2} .
$$

with solution

$c_{t}-\left\{\frac{c_{0}-h^{-1}}{(\beta R)^{1 / A}-h}\right\}(\beta R)^{(t+1) / A}+\left\{\frac{(\beta R)^{1 / A} c_{-1} c_{0}}{(\beta R)^{1 / A}-h}\right\} h^{t+1}$.

Since $(\beta R)^{1 / A}>1$ and $0 \leq h<1$, the first term in equation (A.12) dominates the second term. As $t \rightarrow \infty$, the ratio $c_{t} / c_{t-1}$ tends to $(\beta R)^{1 / A}$. It can also be shown that $c_{t-1} / W_{t}$ tends to $(\beta R)^{-1 / A}-R^{-1}>0$ as $t \rightarrow \infty$.

The RRA coefficient is defined as

$$
\begin{aligned}
R R A & -\frac{-W_{t} v_{11}}{v_{1}} \\
& -\frac{A}{1-h R c_{t-1} /(R-h) w_{t}} \quad(b y(A .9)) \\
& -\frac{A}{1-h\left(R(\beta R)^{-1 / A}-1\right) /(R-h)} \quad \text { (in the steady state). }
\end{aligned}
$$

We use the condition (A.S) to obtain

$$
A \leq R R A \leq \frac{A}{1-h(R-1) /(R-h)}
$$

The upper bound of the RRA coefficient is increasing in $h$. For example, for a large value of $h, h-.9$ and $R-1.03$ we obtain $A \leq R R A \leq 1.3 A$. We 
conclude that the RRA coefficient approximately equals the parameter $A$ and that the approximation is not sensitive to the value of the parameter $h$.

The intertemporal elasticity of substitution in consumption is defined as

$$
\begin{aligned}
& s=\frac{1}{c_{t}} \frac{\partial c_{t}}{\partial \ell \mathrm{ln}} \\
& =\left((\beta R)^{1 / A} c_{t-1} / c_{t}-h(\beta R)^{1 / A} c_{t-2} / c_{t}\right) / A \\
& -\left(1 \cdot h(\beta R)^{-1 / A} / / A\right. \text { (In the steady state). }
\end{aligned}
$$

If $\beta R$ is approximately one, for example, we obtain $s=(1-h) / A$. We conclude that the intertemporal elasticity of substitution is highly sensitive to the parameter h.

The product $s \times$ RRA in the steady state equals

$$
s \times R R A=1-h R^{-1} \text {. }
$$

Whereas the product equals one in the absence of habit persistence $(h-0)$, habit persistence drives a wedge between the RRA coefficient and the inverse of the intertemporal elasticity of substitution In the sense that the product may be substantially below one. 


\section{ACKNOWLEDGEMENTS}

The first author acknowledges financial support from the center for Research in Security Prices at the University of Chicago.

The second author acknowledges financial support from a National Science Foundation research grant and from a gift to the Graduate School of Business, University of Chicago, by Dimensional Fund Advisors. The authors thank Phillip Braun, John Cochrane, J. Kimball Dietrich, Eugene Fama, Lars Hansen, Campbell Harvey, John Heaton, Ravi Jagannathan, Yuming Li, Franz Palm, Peter Rossi, Kenneth Singleton, George Tauchen, an anonymous referee, and participants at seminars at the University of Chicago, the Cleveland Federal Reserve Bank, Columbia University, Duke University, the London Business School, the 1988 American Finance Association, the 1989 European Finance Association and the 1990 Western Finance Association annual meetings for helpful discussions. We thank Ed Allen for numerous discussions and extremely capable research assistance. The authors are solely responsible for the content of this paper. First draft: October, 1987 ; current draft: December, 1990. 


\section{REFERENCES}

Backus, D., A. W. Gregory and C. I. Telmer, 1990, Accounting for forward rates in markets for forward currency, working paper, New York University.

Bossaerts, P. and R. Green, 1989, A General Equilibrium Model of Changing Risk Premia: Theory and Tests, Review of Financial Studles.

Campbe11, J. Y., 1987, Stock Returns and the Term Structure, Journal of Financial Economics 18, 373-399.

Campbel1, J. Y. and Y. Hamao, 1989, Predictable Bond and Stock Returns in the United States and Japan: A Study of Long-Term Capital Market Integration, working paper, Princeton University and the University of California at San Diego.

Campbell, J. Y., and R. J. Shiller, 1988a, The Dividend-Price Ratio and Expectations of Future Dividends and Discount Factors, Review of Financial Studies 3, $195-228$.

Campbel1, J. Y., and R. J. Shiller, 1988b, Stock Prices, Earnings, and Expected Dividends, Journal of Finance 43, 661-676.

Cecchetti, S., P. Lam and N. Mark, 1990, The Equity Premium and the Risk Free Rate: Matching the Moments, working paper, Ohio State University.

Constantinides, G. M., 1990, Habit Formation: A Resolution of the Equity Premium Puzzle, Journal of Political Economy 98, 519-543.

Cutler, D. M., J. Poterba and L. Summers, 1988, International Evidence on the Predictability of Stock Returns, working paper presented at the Center for Research in Security Prices, October, 1988. 
Dunn, K. B., and K. J. Singleton, 1986, Modelling the Term Structure of Interest Rates under Non-Separable Utility and Durability of Goods, Journal of Financial Economics 17, 27-55.

Eichenbaum, M. S., and L. P. Hansen, 1990, Estimating Models with Intertemporal Substitution Using Aggregate Time Series Data, Journal of Business and Economic Statistics, 8, 53-69.

Eichenbaum, M. S., L. P. Hansen, and K. J. Singleton, 1988, A Time Series Analysis of Representative Agent Models of Consumption and Leisure Choices under Uncertainty, Quarterly Journal of Economics 103, 51-78.

English, W. B, J. Miron and D. W. Wilcox, 1989, Seasonal Fluctuations and the Life Cycle Model of Consumption: A Correction, Journal of Political Economy $97,988-991$.

Epstein, L. G., and Zin, S. E. 1989, Substitution, Risk Aversion and the Temporal Behavior of Consumption and Asset Returns: A Theoretical Framework, Econometrica 57, 937-969.

Fama, E., 1984, Information in the Term Structure, Journal of Financial Economics $13,509-528$.

Fama, E. F., and K. R. French, 1988, Dividend Yields and Expected Stock Returns, Journal of Financial Economics 22, 3-25.

Fama, E. F., and G. W. Schwert, 1977, Asset Returns and Inflation, Journal of Financial Economics 5, 115-146.

Ferson, W. E., 1983, Expectations of Real Interest Rates and Aggregate Consumption: Empirical Tests, Journal of Financial and Quantitative Analysis $18,477-497$.

Ferson, W. E. and S. Foerster, 1990, Finite Sample properties of Methods of Moments in Latent Variable Tests of Asset Pricing Models, working 
paper, University of Chicago and the University of Western Ontario.

Ferson, W. E. and C. Harvey, 1990, Seasonality and Consumption-based Asset Pricing, working paper, Duke University and the University of Chicago.

Gallant, R. A., and G. Tauchen, 1989, Seminonparametric Estimation of Conditionally Constralned Heterogeneous Processes: Asset Pricing Applications, Econometrica, 57, $1091-1120$.

Grossman, S. J., A. Melino, and R. J. Shiller, 1987, Estimating the Continuous-Time Consumption Based Asset-Pricing Model, Journal of Business and Economic Statistics 5, 315-327.

Ha11, R. E. 1988, Intertemporal substitution in consumption, Journal of Political Economy $96,339-357$.

Hansen, L. P., 1982, Large Sample Properties of Generalized Method of Moments Estimators, Econometrica 50, 1029-1054.

Hansen, L. P., and R. Jagannathan, 1990, Implications of Security Market Data for Models of Dynamic Economies, Journal of Political Economy, forthcoming.

Hansen, L. P., and K. J. Singleton, 1982, Generalized Instrumental Variables Estimation of Nonlinear Rational Expectations Models, Econometrica 50, $1269-1286$.

Hansen, L. P., and K. J. Singleton, 1983, Stochastic Consumption, Risk Aversion and the Temporal Behavior of Asset Returns, Journal of Political Economy 91, 249-266.

Heaton, J., 1990, The Interaction between Time-Nonseparable Preferences and Time Aggregation, working paper 非181-90-EFA, Massachusetts Institute of Technology.

Keim, D. B., and R. F. Stambaugh, 1986, Predicting Returns in the Stock and 
Bond Markets, Journal of Financial Economics 17, 357-390.

Kocherlakota, N., 1990, On tests of representative consumer asset pricing models, working paper, Northwestern University.

Lo, A. W. and A. C. Mackinlay, 1990, Data Snooping and Biases in Tests of Finincial Models, Review of Financial Studies 3, 431-468.

Mehra, R., and E. C. Prescott, 1985, The Equity Premium: A Puzzle, Journal of Monetary Economics 15, 145-161.

Miron, Jeffrey A., 1986, Seasonal fluctuations and the life cycle-permanent income model of consumption, Journal of Political Economy 94, 1258 1279.

Ryder, H. E., Jr., and G. M. Heal, 1973, Optimal Growth with Intertemporally Dependent Preferences, Review of Economic Studies 40 , $1-31$.

Singleton, K. 1990, On the Specification and Estimation of Representative Consumer Asset Pricing Models, Proceedings of the 6-th world congress of the Econometric Society (forthcoming).

Stambaugh, R., 1988, The information in forward rates: Implications for models of the term structure, Journal of Financial Economics 21 (May), 41-70.

Sundaresan, S.M., 1989, Intertemporally Dependent Preferences and the Volatility of Consumption and Wealth, Review of Financial Studies 2,73-89.

Tauchen, G. 1986, Statistical properties of generalized method-of-moments estimators of structural parameters obtained from financial market data, Journal of Business and Economic Statistics 4, 397-425.

Winder, C. A. and Franz C. Palm, 1990, Stochastic implications of the life cycle consumption model under rational habit formation, working paper, Universicy of Limburg. 
FOOTNOTES

1. Heaton (1990) studies monthly data using a first order approximation of the Euler equation in this paper. He uses lagged consumption and dividends as the information set and he models time-aggregation. Heaton finds evidence for both durability and habit persistence in monthly expenditures. Ilis evidence suggests that the half-life of durability is relatively short and that habit persistence dominates durability at horizons beyond about two months. These results are consistent with our estimates of $b_{1}$, which suggests that the effects of time-aggregation are not a very important factor in the estimates.

2. Given a linear approximation time aggregation increases the order of the $M A$ process by one. In the general, nonlinear Euler equation the results of time-aggregation can be more complex.

3. Specifically, we construct the weighting matrix $W$ using the parameter estimates from the $n$-th stage, use this matrix to find parameters for stage $n+1$ which minimize the quadratic form, and then use the new parameters to update the weighting matrix. The iterations continue until a minimum value of the quadratic form is obtained.

4. The annual data for $1929-49$ are spliced into the annual sums of the quarterly Commerce department data, in real, per capita terms, using 1949 levels as the splicing factor.

5. Price deflators for personal consumption expenditures are only available to us in seasonally adjusted form. We use the seasonally unadjusted components of the CPI for consumer nondurable goods to deflate the nominal nondurables expenditure totals, and the CPI for consumer durables to deflate the durable goods expenditures. In other experiments, we used the overall CPI as the deflator for both categories, and the results were similar.

6. See Lo and Mackinlay (1990) for an analysis of data snooping in financial models. Note that if there is spurious predictability, then it will be difficult for the Euler equation to "explain" this predictability. Such a bias is conservative, given our result that habit persistence helps to explain the predictability through the Euler equation.

7. Deflated returns produce similar results.

8. The GMM estimate of b minimizes a quadratic form which is infinite for $c_{t}+b_{1} c_{-1}-0$ and undefined for $c_{0}+b_{1} c_{1}<0$. Our estimates of $b_{1}$ ensure that the argument of the utiliky function, $c_{t}+b_{1} c-1$ is positive at all dates. In our quarterly (annual, monthly) sample the minimum ratio $\left(c_{t} / c_{t-1}\right)$ is $0.98(0.92, .975)$, verifying that the argument of the utility function is positive at all dates and for all point estimates of $b_{1}$ presented in Tables 3-6. 
9. We repeated the tests in panel 2, except that we used an MA(1) assumption for the error terms in the time separable model and an MA(2) assumption in the one-lag, nonseparable model. The point estimates of the parameters are very similar but the standard errors are typically larger. The goodness-offit statistics are typically smaller than in panel 2. For example, the time separable model is not longer rejected in the five-asset system (the pvalue is 0.44 ) but it is rejected in the two-asset system ( $p$-value- 0.006). The one-lag, nonseparable model is not rejected. Including additional moving average terms, when the autocorrelations are not significant, implies that the estimate of the covariance matrix of the orthogonality conditions will be noisier. We would expect this to reduce the efficiency of the estimates and the power of the goodness-of-fit tests.

10. We repeated the tests in panel 2, using the financial variables at lag two as instruments, but we used alternative moving average assumptions for the error terms (i.e. MA(1) for the time-separable and MA(2) for the one-lag model. These experiments show that the results are robust. In the five-asset system the point estimate of $b$, is -0.87 (standard error 0.03 ). However, none of the models can be rejected by the goodness-of-fit statistics and the standard errors of the coefficients are often larger than in table 5 .

11. Even is the absence of durability two parameters ( $h$ and a) determine the half-life of habit persistence. Three parameters would be needed to isolate the separate effects of durability and habit persistence.

12. The seasonally adjusted consumption levels are given by $c \exp \left(\gamma^{\prime}\left[D-D_{t}\right]\right)$, where $c$ is the unadjusted consumption, $\gamma$ is a vector of three shift parameters relaEive to the first quarter, $D_{t}$ is a vector of durny variables for quarters $2-4$ and $D$ is the vector of sample means of the dumny variables.

13. Miron (1986) included a time-squared term in his regressions for the log of consumption. In a previous version of this paper we followed Miron by including the squared term. Our results using this alternative series were very similar to those reported in Tables 7,8 and 9 .

14. We replicated the tests in Table 6 using only a constant as the instrument and we are unable to reject the hypothesis that $b_{1}$ is zero.

15. Singleton (1990) provides an analysis of Euler equation errors which also suggests that habit persistence improves the fit of consumption models through the time series properties of the data. 


\begin{tabular}{|c|c|c|}
\hline SYMBOL & $\begin{array}{l}\text { FIgure 1: THE INSTRUMENTS } \\
\text { DEFINITION }\end{array}$ & SOURCE \\
\hline VWYLD $(-1)$ & $\begin{array}{l}\text { Dividend yield on the CRSP value-weighted stock } \\
\text { Index. }\end{array}$ & CRSP \\
\hline $\operatorname{DIVDIFF}(-1)$ & $\begin{array}{l}\text { Dividend yield on the CRSP equally-weighted stock } \\
\text { index less the dividend yield of the value- } \\
\text { weighted stock index. }\end{array}$ & CRSP \\
\hline TBLMO & Nominal, one-month Treasury bill rate. & CRSP \\
\hline$P 1(-1)$ & $\begin{array}{l}\text { Inverse of the price level index for the smallest } \\
\text { decile of common stocks, multiplied by the } \\
\text { average of the price level over the previous } \\
\text { year. }\end{array}$ & CRSP \\
\hline $\operatorname{GIPX}(-1)$ & $\begin{array}{l}\text { Annual growth rate of the U.S. industrial } \\
\text { production index. }\end{array}$ & $\begin{array}{l}\text { Federal } \\
\text { Reserve } \\
\text { Bulletin }\end{array}$ \\
\hline $\operatorname{LSLOPE}(-1)$ & $\begin{array}{l}\text { Average monthly yield-to-maturity of } \\
\text { corporate bonds rated Aaa by Moody's Investor } \\
\text { Services, less the one-month Treasury bill rate. }\end{array}$ & $\begin{array}{l}\text { Federal } \\
\text { Reserve } \\
\text { Bulletin }\end{array}$ \\
\hline $\operatorname{SSLOPE}(-1)$ & $\begin{array}{l}\text { Three-month Treasury bill rate less the one- } \\
\text { month Treasury bill rate. }\end{array}$ & CRSP \\
\hline $\operatorname{CBPREM}(-1)$ & $\begin{array}{l}\text { Average monthly yield-to-maturity of } \\
\text { corporate bonds rated Baa by Moody's Investor } \\
\text { Services, less the Aaa corporate bond yield. }\end{array}$ & $\begin{array}{l}\text { Federal } \\
\text { Reserve } \\
\text { Bulletin }\end{array}$ \\
\hline
\end{tabular}

Notes: CRSP stands for the Center for Research in Security Prices at the University of Chicago. 
Consumption growth rates are for real per capita expendicures. Returns are arichmetic nominal rates of return per annum. The return of treasury bills corresponds to a strategy of rolling over one-month bills each month. DecN refers to a value weighted portfollo of common stocks of the N-th size decile. Cbprem is the annualized yield-to-maturity of corporate bonds rated BAA by Moodys investor services less the yield of AAA rated bonds. TBIMO is the continuously-compounded rate of return of a 1 -month treasury bill. Vwyld in the dividend yield on the CRSP value-weighted index, measured as the previous 12 -months dividend payments divided by the level of the Index. Divdiff is the difference between the dividend yield of the CRSP equally-welghted index and that of the value-weighted index. LSlope is the AAA corporate bond yleld less the one-month treasury bill rate. Sslope is the difference between the three-month and one the one-month treasury bill yield. Gipx is the continuouslycompounded annual growth rate of the index of Industrial production. Pl is the inverse of index level of prices of the smallest decile of common stocks on the NYSE. relative to the average of the level for the preceding 12 months. X-11 indicates data seasonally adjusted by the Commerce Department using the $X-11$ program. DSA Indicates consumption data seasonaliy adjusted by the authors using dumay varlables. NSA denotes a not seasonally adjusted component of the CPI.

\begin{tabular}{llllllll}
\hline Part I: Quarterly Data & \multicolumn{3}{c}{ Autocorrelations } \\
Variable & Mean Std. Dev. $\quad \rho_{1}$ & $\rho_{2}$ & $\rho_{3}$ & $\rho_{4}$ & $\rho_{8}$ & $\rho_{12}$ & $\rho_{24}$
\end{tabular}

Real Consumption Growth Rates (1948.2-1986.2: 153 observations, in percent)

$\begin{array}{llllllrrrrrr}\text { Nondurables (X-11) } & 0.302 & 0.852 & 0.07 & 0.08 & 0.12 & -0.05 & -0.17 & -0.01 & -0.01 & -0.16 \\ \text { Durables (X-11) } & 0.942 & 4.236 & -0.09 & 0.15 & -0.14 & -0.03 & -0.20 & -0.09 & 0.03 & 0.02 \\ \text { Nondurables (DSA) } & 0.000 & 2.233 & -0.31 & -0.21 & -0.14 & 0.56 & 0.40 & 0.50 & 0.31 & 0.11 \\ \text { Durables (DSA) } & 0.167 & 5.236 & -0.24 & 0.22 & -0.27 & 0.19 & -0.02 & 0.01 & -0.01 & 0.01\end{array}$

Asset Returns (1947.1-1986.4: 160 observations)

$\begin{array}{lrrrrrrrrrr}1 \text { Month bill } & 0.012 & 0.008 & 0.96 & 0.92 & 0.90 & 0.87 & 0.75 & 0.68 & 0.51 & 0.38 \\ \text { Government Bond } & 0.012 & 0.049 & -0.06 & 0.07 & 0.15 & 0.06 & -0.06 & -0.01 & 0.00 & -0.11 \\ \text { Stocks: Decl } & 0.047 & 0.133 & 0.01 & -0.11 & -0.08 & 0.15 & -0.04 & 0.13 & -0.07 & 0.15 \\ \text { Stocks: Decs } & 0.037 & 0.099 & 0.10 & -0.10 & -0.06 & -0.01 & -0.07 & 0.03 & -0.17 & 0.09 \\ \text { Stocks: Decl0 } & 0.029 & 0.071 & 0.13 & -0.06 & -0.05 & -0.01 & -0.07 & 0.05 & -0.13 & 0.09\end{array}$

Instrumental Varlables (1947.1-1987.3: 163 observations)

\begin{tabular}{|c|c|c|c|c|c|c|c|c|c|c|}
\hline Cbprem & 0.946 & 0.474 & 0.92 & 0.85 & $0 . \mathrm{BO}$ & 0.73 & 0.54 & 0.41 & 0.39 & 0.26 \\
\hline Tblmo & 0.047 & 0.031 & 0.91 & 0.90 & 0.88 & 0.85 & 0.75 & 0.67 & 0.50 & 0.37 \\
\hline Vuryld & 0.041 & 0.011 & 0.94 & 0.88 & 0.83 & 0.78 & 0.64 & 0.55 & 0.08 & .0 .19 \\
\hline divdiff & -0.002 & 0.005 & 0.92 & 0.87 & 0.79 & 0.74 & 0.53 & 0.44 & 0.24 & 0.1 \\
\hline Islope & 0.019 & 0.013 & 0.66 & 0.61 & 0.55 & 0.45 & 0.17 & -0.04 & 0.02 & 0.02 \\
\hline Gipx & 0.037 & 0.066 & 0.81 & 0.47 & 0.10 & -0.25 & .0 .16 & -0.05 & -0.00 & -0.00 \\
\hline P1 & 0.922 & 0.149 & 0.60 & 0.27 & 0.06 & -0.02 & .0 .17 & 0.08 & -0.29 & 0.00 \\
\hline SSlope & 0.323 & 0.455 & 0.15 & 0.35 & 0.21 & 0.50 & 0.37 & 0.07 & 0.15 & 0.06 \\
\hline
\end{tabular}


Inflation Rates (1948.2-1986.2: 153 observations, In percent)

\begin{tabular}{|c|c|c|c|c|c|c|c|c|c|c|c|}
\hline Nondurables & $(x-11)$ & 0.906 & 1.084 & 0.69 & 0.54 & 0.48 & 0.31 & 0.09 & 0.18 & 0.23 & .0 .0 \\
\hline Dural & $(x+11)$ & 0.694 & 1.218 & 0.08 & 0.09 & 0.14 & 0.08 & 0.36 & 0.00 & & \\
\hline Nondurables & (NSA) & 0.904 & 1.366 & 0.44 & 0.33 & 0.43 & 0.34 & 0.05 & 0.16 & 0.20 & \\
\hline Durables & (NSA) & 0.789 & 1.260 & 0.37 & 0.36 & 0.26 & 0.49 & 0.41 & 0.34 & 0.25 & 0 \\
\hline
\end{tabular}

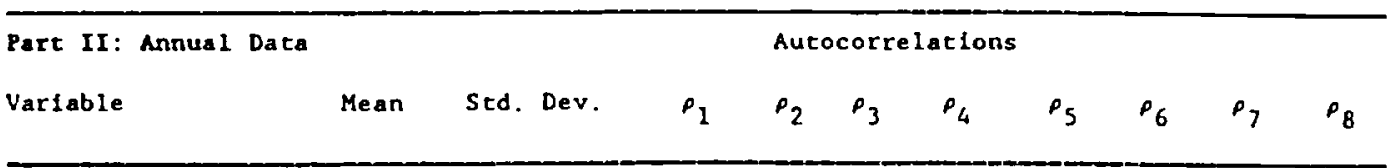

Real Consumption Crowth Rates (1930-1986: 57 observacions)

$\begin{array}{llllllllllllllllllllllllllllll}\text { Nondurables } & 0.014 & 0.031 & 0.41 & 0.10 & -0.09 & -0.21 & -0.02 & -0.14 & -0.05 & -0.08\end{array}$ $\begin{array}{lllllllllllllllllllllllll}\text { Durables } & 0.040 & 0.164 & 0.26 & -0.09 & -0.28 & -0.22 & -0.02 & -0.00 & -0.01 & -0.26\end{array}$

Asset Returns (1926-1986: 61 observations)

$\begin{array}{lllllllrrrrr}1 \text { Month b111 } & 0.035 & 0.034 & 0.92 & 0.85 & 0.80 & 0.75 & 0.70 & 0.64 & 0.59 & 0.53 \\ \text { Covernment Bond } & 0.046 & 0.085 & 0.10 & 0.02 & 0.11 & 0.10 & -0.14 & 0.09 & -0.10 & -0.00 \\ \text { Stocks: Dec1 } & 0.228 & 0.469 & 0.15 & -0.15 & -0.13 & -0.34 & -0.14 & -0.14 & -0.03 & 0.07 \\ \text { Stacks: Dec5 } & 0.153 & 0.290 & 0.04 & -0.15 & -0.09 & -0.20 & -0.03 & -0.14 & 0.01 & -0.04 \\ \text { Stocks: Dec10 } & 0.108 & 0.195 & 0.04 & -0.21 & -0.04 & -0.14 & -0.01 & -0.07 & 0.10 & 0.05\end{array}$

Instrumental Vartables (1926-1986: 61 observations)

$\begin{array}{lrrrrrrrrrr}\text { Tblmo } & 0.033 & 0.029 & 0.91 & 0.84 & 0.79 & 0.76 & 0.71 & 0.66 & 0.59 & 0.53 \\ \text { Vwyld } & 0.045 & 0.014 & 0.62 & 0.30 & 0.20 & 0.21 & 0.29 & 0.30 & 0.22 & 0.15 \\ \text { divdiff } & 0.004 & 0.008 & 0.70 & 0.39 & 0.28 & 0.32 & 0.35 & 0.33 & 0.30 & 0.19 \\ \text { Pl } & 1.004 & 0.334 & 0.26 & 0.02 & -0.10 & -0.21 & -0.16 & 0.16 & 0.11 & 0.09 \\ \text { SSlope } & 0.342 & 0.594 & 0.59 & 0.38 & 0.12 & 0.20 & 0.34 & 0.32 & 0.22 & 0.13\end{array}$

Inflation Races (1930-1986:57 observations)

$\begin{array}{lllllllllllllllllllllllllllllllll}\text { Nondurables } & 0.031 & 0.133 & 0.32 & -0.06 & -0.28 & -0.32 & -0.06 & 0.00 & -0.07 & -0.05\end{array}$ Durables 


\begin{tabular}{llllllllll}
\hline Part III: Monthly Data & \multicolumn{8}{c}{ Autocorrelations } \\
Varlable & Mean Std. Dev. $\quad \rho_{1}$ & $\rho_{2}$ & $\rho_{3}$ & $\rho_{4}$ & $\rho_{8}$ & $\rho_{12}$ & $\rho_{24}$ & $\rho_{36}$
\end{tabular}

Real Consumption Growch Rates (1959.02-1986.12: 335 observations)

$\begin{array}{lrllllllllll}\text { Nondurables } & (X-11) & 0.0010 & 0.0078 & -0.36 & 0.03 & 0.11 & -0.08 & 0.01 & -0.04 & -0.24 & -0.06 \\ \text { Services } & (X-11) & 0.0022 & 0.0038 & -0.16 & 0.00 & -0.03 & -0.08 & 0.10 & -0.04 & -0.05 & 0.09 \\ \text { Durables } & (X-11) & 0.0036 & 0.0300 & -0.11 & -0.09 & -0.17 & -0.01 & 0.05 & 0.11 & -0.12 & -0.02 \\ \text { Tocal } & (X-11) & 0.0019 & 0.0059 & -0.14 & -0.01 & -0.01 & 0.00 & 0.05 & 0.02 & -0.21 & -0.06\end{array}$

Asset Returns (1959.01-1986.12:336 observations)

$\begin{array}{lrlrrrrrrrrr}\text { I Month bill } & 0.0048 & 0.0024 & 0.96 & 0.93 & 0.90 & 0.88 & 0.83 & 0.76 & 0.58 & 0.45 \\ \text { Covernment Bond } & 0.0052 & 0.0290 & 0.02 & 0.02 & -0.15 & 0.06 & 0.01 & -0.05 & -0.07 & 0.01 \\ \text { Stocks: Decl } & 0.0151 & 0.0714 & 0.08 & -0.02 & -0.03 & -0.01 & -0.12 & 0.23 & 0.03 & 0.10 \\ \text { Stocks: Dec5 } & 0.0117 & 0.0536 & 0.12 & -0.03 & 0.02 & 0.04 & -0.13 & 0.10 & 0.01 & 0.00 \\ \text { Stocks: Dec10 } & 0.0078 & 0.0405 & -0.03 & -0.02 & 0.05 & 0.08 & -0.02 & 0.07 & -0.02 & -0.03\end{array}$

Instrumental Varlables (1958.12-1986.11: 336 observations)

$\begin{array}{lrrrrrrrrrr}\text { Cbpren } & 0.011 & 0.005 & 0.97 & 0.93 & 0.91 & 0.89 & 0.78 & 0.67 & 0.47 & 0.31 \\ \text { Tblmo } & 0.059 & 0.029 & 0.96 & 0.93 & 0.90 & 0.88 & 0.84 & 0.77 & 0.58 & 0.45 \\ \text { Vwyld } & 0.038 & 0.009 & 0.98 & 0.96 & 0.94 & 0.92 & 0.82 & 0.75 & 0.67 & 0.66 \\ \text { divdiff } & 0.003 & 0.004 & 0.97 & 0.96 & 0.94 & 0.92 & 0.85 & 0.81 & 0.54 & 0.34 \\ \text { LSlope } & 0.020 & 0.015 & 0.89 & 0.80 & 0.73 & 0.67 & 0.57 & 0.40 & 0.08 & -0.16 \\ \text { Gipx } & 0.039 & 0.058 & 0.96 & 0.90 & 0.81 & 0.72 & 0.37 & -0.02 & -0.33 & -0.07 \\ \text { Pl } & 2.548 & 47.67 & 0.07 & 0.11 & 0.36 & -0.11 & -0.03 & -0.05 & 0.03 & 0.01 \\ \text { SSlope } & 0.434 & 0.432 & 0.34 & 0.30 & 0.20 & 0.19 & 0.22 & 0.43 & 0.26 & 0.02\end{array}$

Inflation Rates (1959.02-1986.12: 335 observations)

$\begin{array}{lrllllllllrrr}\text { Nondurables } & (X-11) & 0.004 & 0.005 & 0.36 & 0.36 & 0.23 & 0.31 & 0.27 & 0.14 & 0.07 & -0.04 \\ \text { Durables } & (X-11) & 0.003 & 0.005 & 0.01 & 0.23 & 0.11 & 0.13 & 0.13 & 0.11 & -0.02 & 0.03 \\ \text { Services } & (X-11) & 0.004 & 0.003 & 0.58 & 0.65 & 0.64 & 0.59 & 0.60 & 0.60 & 0.51 & 0.45 \\ \text { Total } & (X-11) & 0.004 & 0.003 & 0.49 & 0.56 & 0.44 & 0.51 & 0.45 & 0.45 & 0.29 & 0.23\end{array}$


TABLE 2: CORRELATIONS OF THE INSTRUMENTS

Cbprem is the annualized yield-to-maturity of corporate bonds rated BAA by Moodys investor services less the yleld of AAA rated bonds. TBIMO is the continuously-compounded rate of return of a 1 -month treasury bill. Vwyld in the dividend yield on the CRSP, value-weighted index, measured as the previous 12 months dividend payments divided by the level of the index. Divdiff is the difference between the dividend yield of the CRSP equally-weighted index and that of the value-weighted index. LSlope is the AAA corporate bond yield less the one-month treasury bill rate. Sslope is the difference between the threemonth and one the one-month treasury bill yield. Gipx is the continuouslycompounded annual growth rate of the index of Industrial production. P1 is the inverse of index level of prices of the smallest decile of common stocks on the NYSE, relative to the average of the level for the preceding 12 months.

PART I: QUARTERLY DATA (SAMPLE PERIOD 1948.1-1987.3: 163 observations)

$\begin{array}{lcccccccc}\text { Cbprem } & \begin{array}{c}\text { Cbprem } \\ 1.000\end{array} & \text { Tblmo } & \text { Vwyld } & \text { Divdiff } & \text { LSlope } & \text { Gipx } & \text { P1 } & \text { SSlope } \\ \text { Tblmo } & 0.674 & 1.000 & & & & & & \\ \text { Vwyld } & 0.178 & 0.015 & 1.000 & & & & & \\ \text { Divdiff } & -0.476 & -0.598 & -0.036 & 1.000 & & & & \\ \text { LSlope } & 0.512 & -0.017 & 0.017 & -0.287 & 1.000 & & & \\ \text { Gipx } & -0.448 & -0.089 & -0.181 & -0.152 & -0.222 & 1.000 & & \\ \text { Pl } & -0.06 & 0.05 & 0.11 & 0.45 & -0.12 & -0.14 & 1.000 & 1.000 \\ \text { SSlope } & 0.44 & 0.37 & 0.05 & -0.28 & 0.29 & -0.17 & 0.03 & 1.000\end{array}$

PART II: ANNUAL DATA (SAMPLE PERIOD 1926-1986: 61 observations)

$\begin{array}{lrrcrr} & \text { Tblmo } & \text { Vwyld } & \text { Divdiff } & \text { P1 } & \text { Slope } \\ \text { Tblmo } & 1.00 & & & & \\ \text { Vwyld } & -0.23 & 1.00 & & & \\ \text { Divdiff } & 0.10 & -0.21 & 1.00 & & \\ \text { Pl } & -0.07 & 0.54 & 0.09 & 1.00 & \\ \text { SSlope } & 0.69 & -0.15 & 0.09 & -0.12 & 1.00\end{array}$

PART III: MONTHLY DATA (SAMPLE PERIOD 1958.12-1986.11: 336 observations)

\begin{tabular}{|c|c|c|c|c|c|c|c|c|}
\hline Cbprem & $\begin{array}{c}\text { Cbprem } \\
1.0\end{array}$ & Tblmo & Vwyld & Divdiff & Lslope & Gipx & P1 & Sslope \\
\hline Tbimo & 0.59 & 1.0 & & & & & & \\
\hline Vwy ld & 0.68 & 0.74 & 1.0 & & & & & \\
\hline Divdiff & -0.42 & -0.50 & -0.56 & 1.0 & & & & \\
\hline Ls lope & 0.49 & -0.18 & 0.18 & -0.25 & 1.0 & & & \\
\hline Gipx & -0.56 & -0.20 & -0.37 & -0.013 & -0.23 & 1.0 & & \\
\hline Pl & 0.14 & 0.16 & 0.09 & -0.10 & -0.014 & 0.013 & 1.0 & \\
\hline Sslope & 0.39 & 0.25 & 0.36 & -0.23 & 0.30 & -0.23 & 0.066 & 1.0 \\
\hline
\end{tabular}


Table 3

Test results using monthly returns data for 1959.5 - 1986.10 (330 observations) and monthly consumption. The model assumes that a representative agent maximizes:

$$
E_{0}\left[(1-A)^{-1} \sum_{t=0}^{\infty} \beta^{t} C_{t}^{1-A}\right]
$$

where $c_{t}-c_{t}+b_{1} c_{t-1}$ and $c_{t}$ is consumption expenditures at date $t$. $A$ is the concavity parameter, $\beta$ is the rate of time discount, and $b_{1}$ is the parameter representing habit persistence $\left(b_{1}<0\right)$ or durability $\left(b_{1}>0\right)$. In the timeseparable model, $b_{1}$ is set equal to zero. Estimation is by generalized method of moments (GMM). Asymptotic standard errors (s.e) are in parentheses. P-value is the probability that a $x^{2}$ variate exceeds the minimized sample value of the GMM criterion function. The tests use a system of five asset returns: the common stock portfolios from size deciles 1,5 and 10, a long-term government bond and a one-month Treasury bill. Real returns are the nominal returns deflated by the price deflator corresponding to the measure of consumption.

\begin{tabular}{|c|c|c|c|c|}
\hline & $\begin{array}{c}\beta \\
(s . e .)\end{array}$ & $\begin{array}{c}A \\
(s . e)\end{array}$ & $\left(s . \frac{1}{e}\right)$ & $\begin{array}{c}x^{2} \\
(p-v a l u e)\end{array}$ \\
\hline $\begin{array}{l}\text { PANEL 1: USING THE MOST RECENT } \\
\text { b } \\
\text { INSTRUMENTS: } \\
\text { CONSUMPTION: }\end{array}$ & LAGS OF THE & INSTRUMEN & & \\
\hline Cons.\& Rets. $(-1)$ Nondurables & $\begin{array}{c}0.993 \\
(0.000) \\
1.001 \\
(0.001)\end{array}$ & $\begin{array}{c}0.305 \\
(0.073) \\
2.112 \\
(0.531)\end{array}$ & $\begin{array}{c}0^{a} \\
0.427 \\
(0.065)\end{array}$ & $\begin{array}{c}57.23 \\
(0.006) \\
40.25 \\
(0.150)\end{array}$ \\
\hline Financial $(-1)$ & $\begin{array}{c}0.999 \\
(0.000) \\
0.838 \\
(0.062)\end{array}$ & $\begin{array}{c}-0.046 \\
(0.186) \\
8.437 \\
(10.397)\end{array}$ & $\begin{array}{c}0^{a} \\
-0.717 \\
(0.194)\end{array}$ & $\begin{array}{c}77.87 \\
(0.001) \\
45.02 \\
(0.347)\end{array}$ \\
\hline
\end{tabular}


table 3 page 2

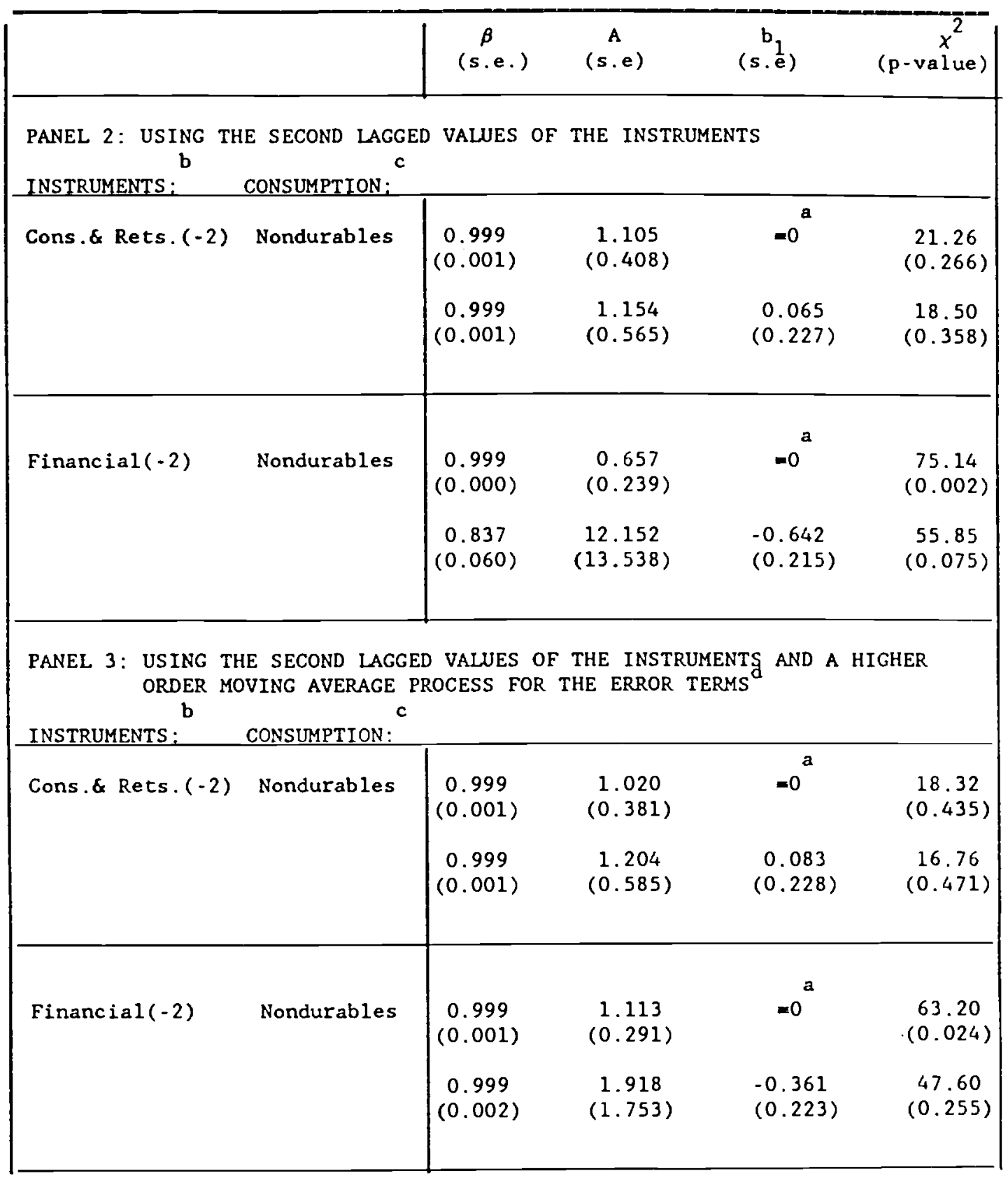


table 3 page 3

a An " $=0$ " Indicates that the parameter is set to zero.

$b$ The financial instruments consist of a constant and the eight variables summarized in figure 1 . The notation $(-1)$ indicates that the variables are lagged back one month relative to the asset returns in the Euler equations. When the financial instruments are denoted "financial $(-2)$," they are lagged back two months relative to the asset returns in the Euler equations. "Cons. \& Rets." denotes an instrument set composed of: a constant, the growth of the consumption measure, the real treasury bill return and the real return of the size portfolio from the smallest dectle of firms. When denoted "Cons.\& Rets.(-1), each of the variables are lagged one period and two perlods back relative to the asset returns in the Euler equation, and there are seven instruments. When the instruments are Cons.\& Rets. (-2), the lagged consumption and returns are lagged back two periods only and there are only four instruments.

c Monthly consumption data are real, per capita consumer expenditures for nondurable goods.

d In panel 3, the error terms are assumed to follow an MA(1) process when the time-separable model $\left(b_{1}=0\right)$ is estimated and an $M A(2)$ process when the one-lag model is estimated. 
Table 4

Tests Results Using Quarterly Returns Data for 1948:2 - 1986:2 (153 observations). The model assumes that a representative agent maximizes:

$$
E_{0}\left[(1-A)^{-1} \sum_{t=0}^{\infty} \beta C_{t}^{t-A}\right]
$$

where $c_{t}-c_{t}+b_{1} c_{t-1}$ and $c_{t}$ is real, per capita nondurables consumption expenditures at date $t$. The consumption expenditures are seasonally-adjusted by the Commerce department using the $X-11$ seasonal adjustment program. $A$ is the concavity parameter, $\beta$ is the rate of time discount, and $b_{1}$ is the parameter representing habit persistence $\left(b_{1}<0\right)$ or durability $\left(b_{1}>0\right)$. Estimation is by generalized method of moments (GMM). Asymptotic standard errors are in parentheses. P-value is the probability that a $\chi^{2}$ variate exceeds the minimized sample value of the GMM criterion function. DecN is the real return of common stocks from market value decile $N$. The real returns are the nominal returns deflated by the nondurables price deflator.

\begin{tabular}{|c|c|c|c|c|}
\hline & A & $b_{1}$ & $x^{2}$ & -value \\
\hline \multicolumn{5}{|c|}{ PANEL 1: USING THE FINANCIAL INSTRUMENTS' MOST RECENT LAGGED VALUES ${ }^{b}$} \\
\hline $\begin{array}{l}\text { System: Treasury Bill } \\
\text { Government Bond } \\
\text { Stocks: Decl } \\
\text { Stocks: Dec5 } \\
\text { Stocks: Decl0 }\end{array}$ & $\begin{array}{cc}1.042 & 6.31 \\
(0.009) & (1.31) \\
& \\
0.883 & 0.78 \\
(0.049) & (1.19)\end{array}$ & $\begin{array}{l}\equiv 0^{a} \\
-0.95 \\
(0.05)\end{array}$ & $\begin{array}{l}61.43 \\
37.08\end{array}$ & $\begin{array}{l}0.034 \\
0.686\end{array}$ \\
\hline $\begin{aligned} \text { System: Treasury Bill } \\
\text { Stocks: Declo }\end{aligned}$ & $\begin{array}{cc}0.995 & -0.36 \\
(0.003) & (0.40) \\
& \\
0.575 & 4.94 \\
(0.162) & (8.71)\end{array}$ & $\begin{array}{l}\equiv 0 \\
-0.95 \\
(0.08)\end{array}$ & $\begin{array}{l}38.69 \\
22.36\end{array}$ & $\begin{array}{l}0.001 \\
0.099\end{array}$ \\
\hline
\end{tabular}




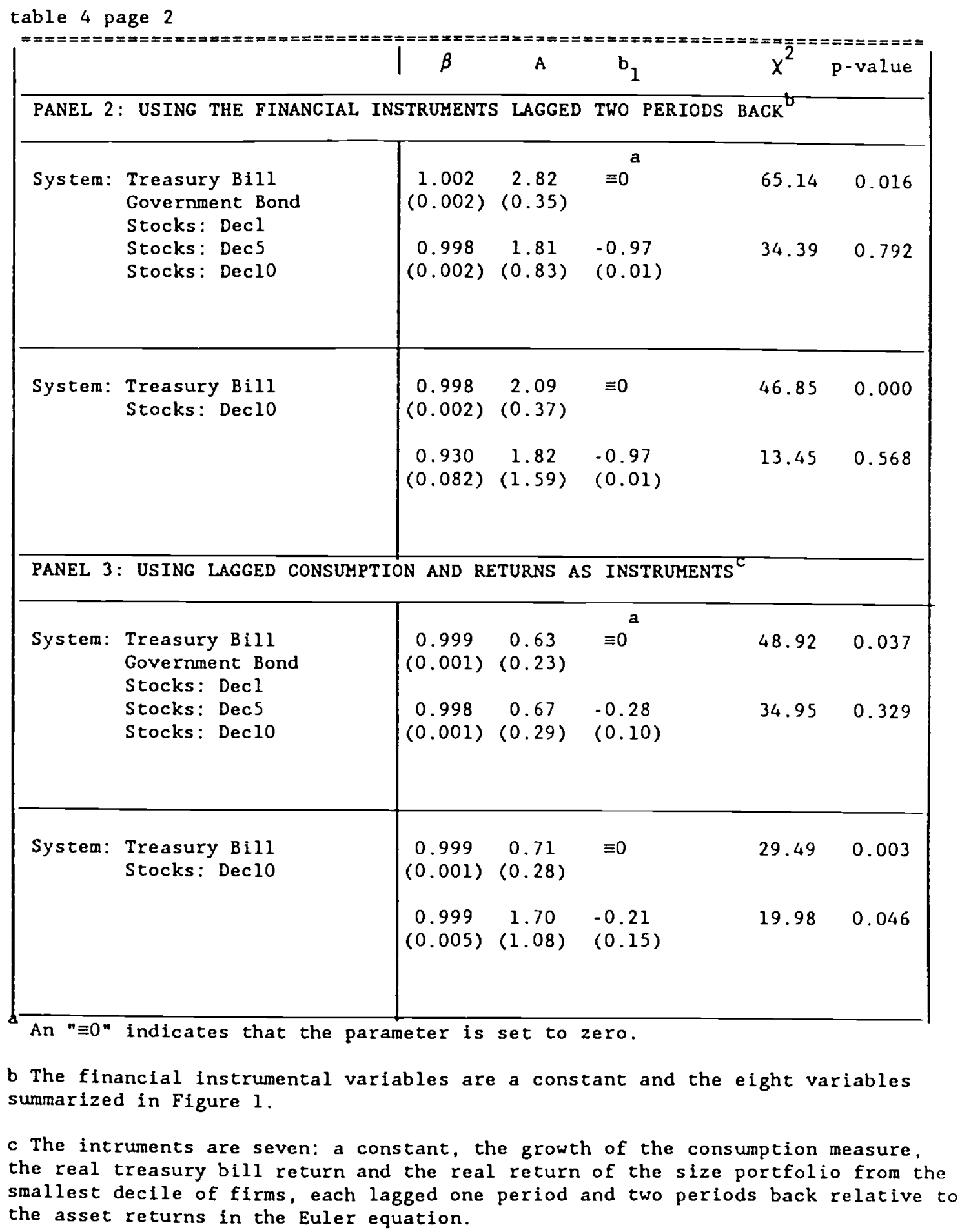


Table 5

Tests Results Using Annual Returns for 1932 - 1984 (53 observations). The model assumes that a representative agent maximizes:

$$
E_{0}\left[(1-A)^{-1} \sum_{t=0}^{\infty} B^{t} C_{t}^{1-A}\right]
$$

where $c_{t}-c_{t}+b_{1} c_{t-1}$ and $c_{t}$ is real, per capita nondurables consumption expenditures at date $t$. A is the concavity parameter, $\beta$ is the rate of time discount, and $b_{1}$ is the parameter representing habit persistence $\left(b_{1}<0\right)$ or durability $\left(b_{1}>0\right)$. Estimation is by generalized method of moments (GMM). Standard errors are in parentheses. P-value is the probability that a $\chi^{2}$ variate exceeds the minimized sample value of the GMM criterion function. DecN is the real return of common stocks from market value decile $N$. The real returns are the nominal returns deflated by the nondurables price deflator.

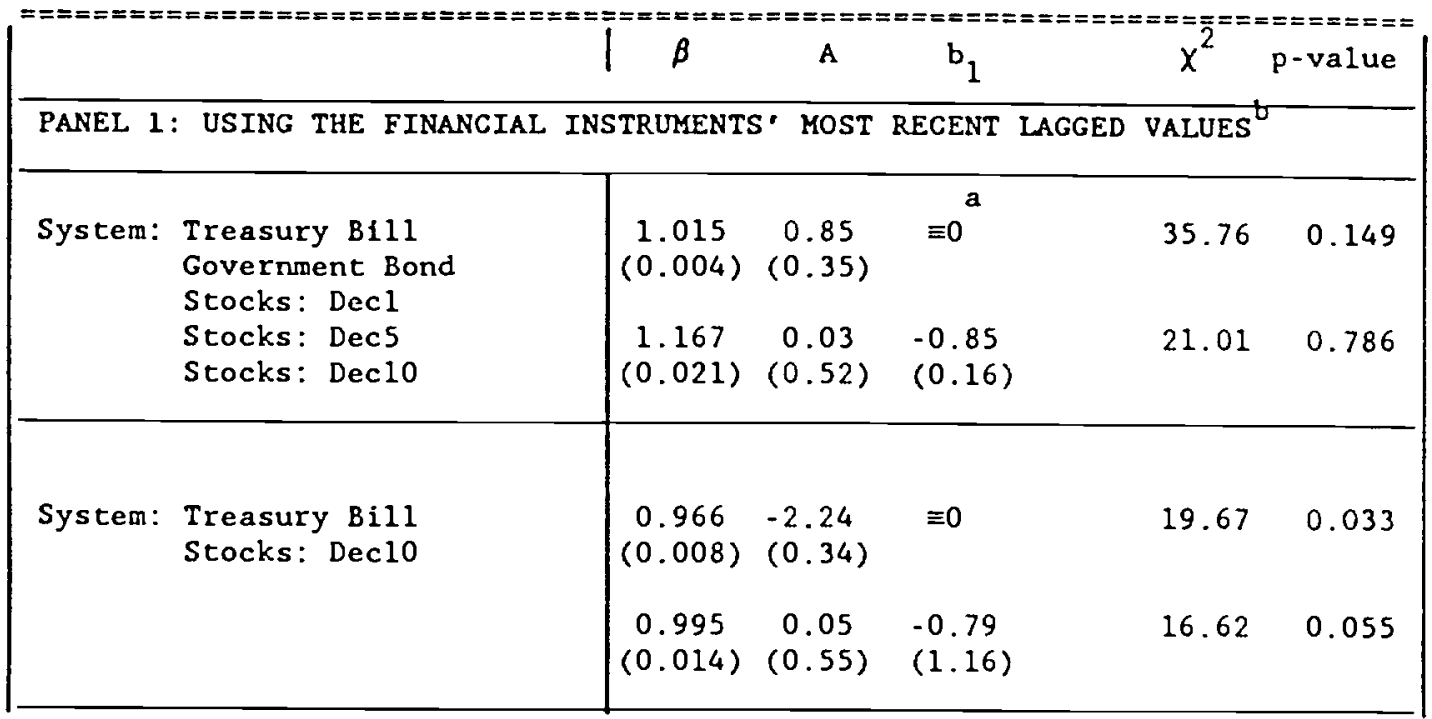


table 5 page 2

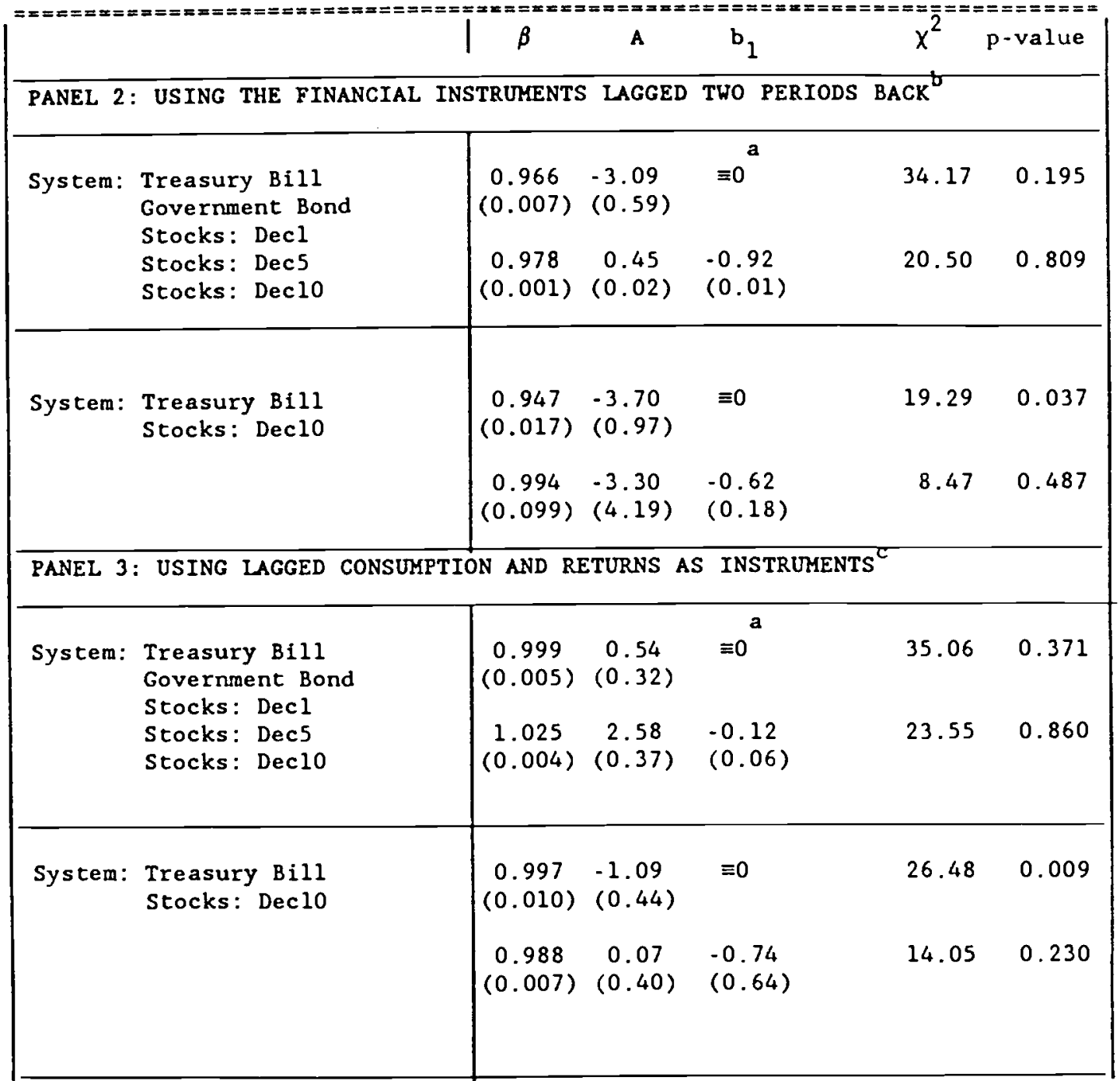

a An " $=0 "$ indicates that the parameter is set to zero.

b The financial instrumental variables are a constant and the eight variables summarized in Figure 1.

c The intruments are seven: a constant, the growth of the consumption measure, the real treasury bill return and the real return of the size portfolio from the smallest decile of firms, each lagged one period and two periods back relative to the asset returns in the Euler equation. 


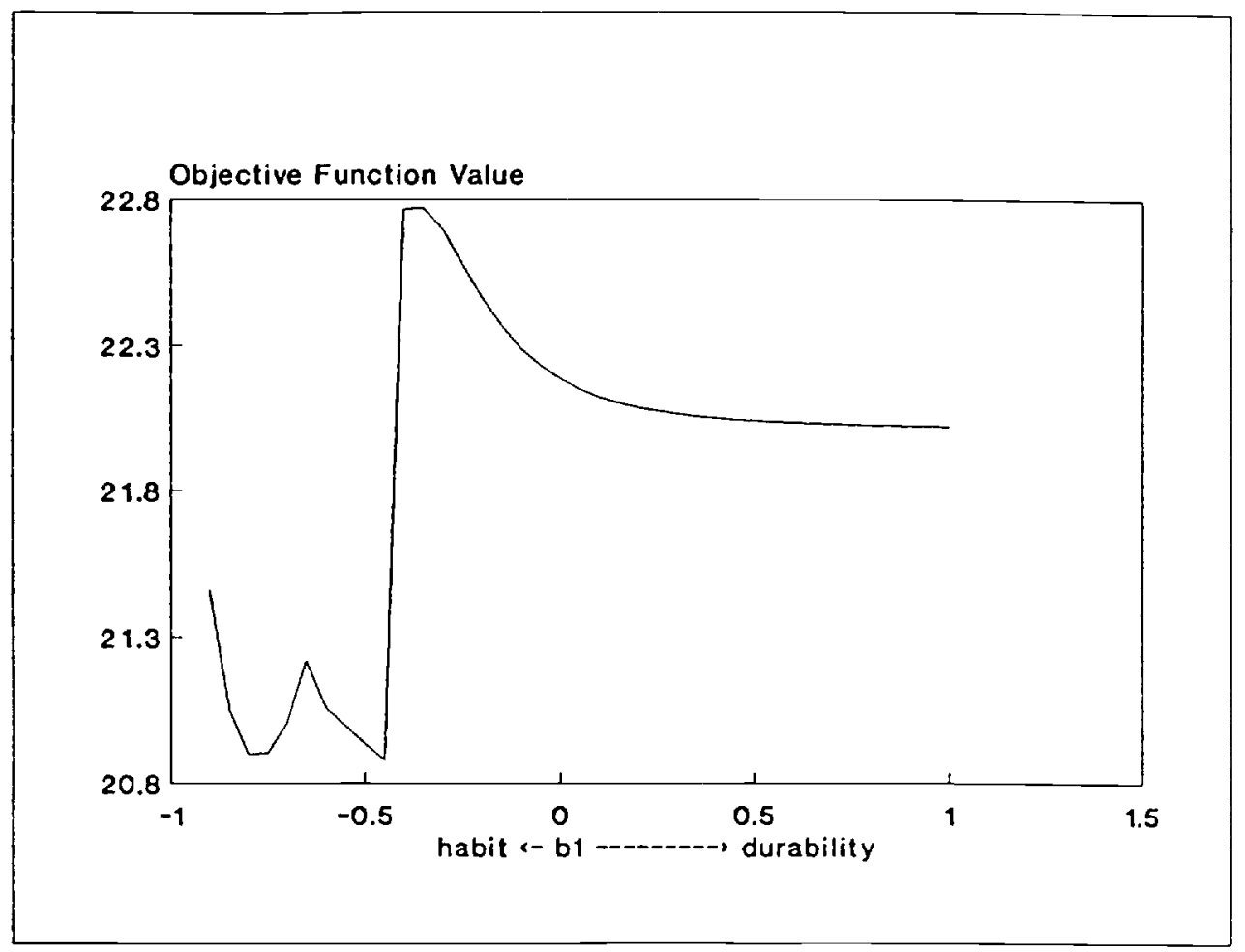

Figure 2: Sensitivity of the Objective Function to the Nonseparability Parameter

The $y$-axis is the value of the generalized method of moments objective function, minimized over the choice of the parameters $A$ and $\beta$, for given values of $b_{1}$. The $b$ values are shown on the $x$-axis. Negative values indicate habit persistence and positive values indicate durability of goods. The model assumes that a representative agent maximizes:

$$
E_{0}\left[(1-A)^{-1} \sum_{t=0}^{\infty} \beta^{t} C_{t}^{1-A}\right]
$$

where

$$
c_{t}=c_{t}+b_{1} c_{t-1}
$$

and $c_{t}$ is consumption expenditures at date $t$.

The consumption data are annual expenditures for consumer nondurable goods. The real asset returns are common stocks from size deciles 1,5, and 10, a long term government bond and the return to rolling over one-month treasury bills for $1932-1984$ (53 observations). 
Table 6

Tests for the importance of a nonzero nonseparability parameter with a moving average error structure. Quarterly returns data are for 1948.2-1986.2 (153 observations) and the annual returns data are for 1932-1984 (53 observations). The model assumes that a representative agent maximizes:

$$
E_{0}\left[(1-A)^{-1} \sum_{t=0}^{\infty} \beta^{t} C_{t}^{1-A}\right]
$$

where $c_{t}-c_{t}+b_{1} c_{t-1}$ and $c_{t}$ is nondurables consumption expenditures at date $t$. $A$ is the concavity parameter, $\beta$ is the rate of time discount, and $b_{1}$ is the parameter representing habit persistence $\left(b_{1}<0\right)$ or durability $\left(b_{1}>0\right)$. Estimation is by generalized method of moments (GMM), using a weighting matrix which assumes that the error terms are autocorrelated at lag one and uncorrelated at longer lags. P-value is the probability that a $\chi^{2}$ variate exceeds the minimized sample value of the test statistic. The $x^{2}(1)$ statistic is the difference between the GMM criterion functions, imposing the hypothesis that $b_{1}$ is zero and leaving $b_{1}$ unrestricted. The $t\left(b_{1}\right)^{2}$ statistic is the square of the $t$ statistic of $b_{1}$ from tables 4 and 5 .

\begin{tabular}{|l|cccc}
\hline & $x^{2}(1)$ & $(p-v a l u e)$ & $t\left(b_{1}\right)^{2}$ & $(p-v a l u e)$ \\
\hline QUARTERLY DATA: & & & \\
System: Five Assets & 23.86 & 0.00 & 329.9 & 0.00 \\
System: Two Assets & 4.06 & 0.04 & 126.1 & 0.00 \\
\hline ANNUAL DATA: & & & & \\
\hline System: Five Assets & 9.75 & 0.00 & 28.22 & 0.00 \\
System: Two Assets & 1.90 & 0.17 & 0.46 & 0.49 \\
\hline
\end{tabular}




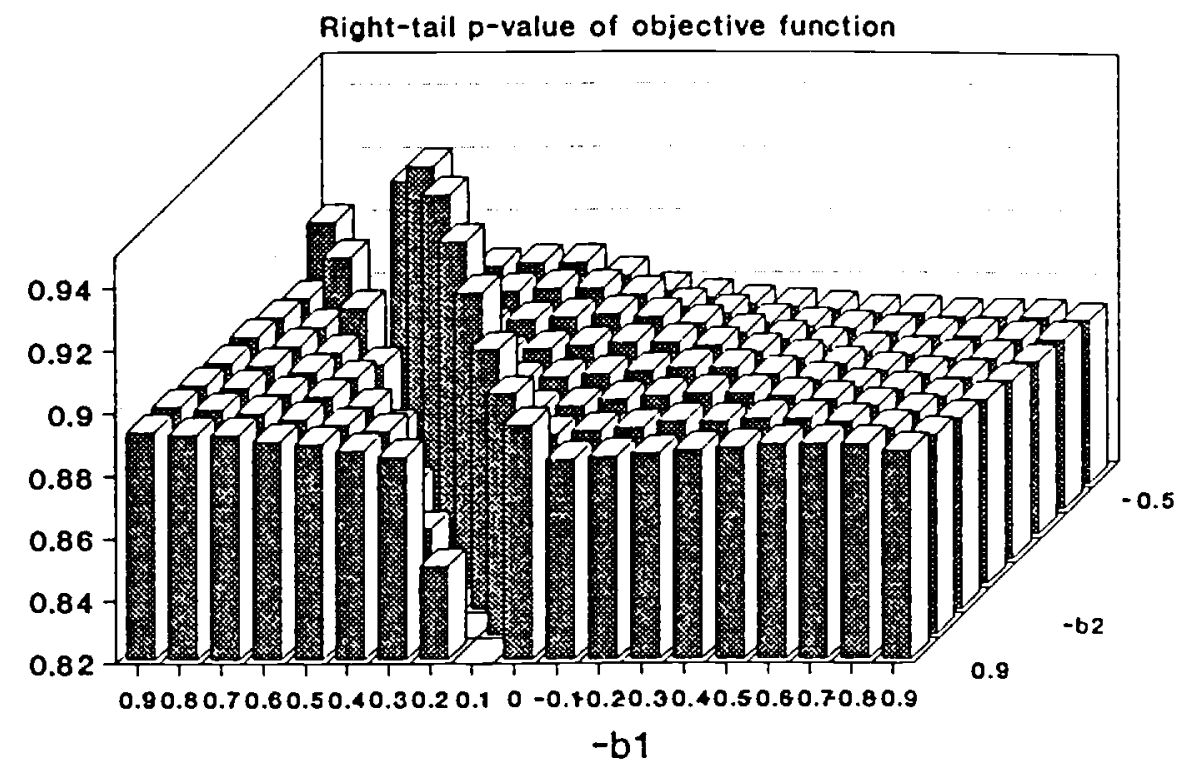

Figure 3: Sensitivity of the objective Function to the Nonseparability Parameters in a Two-lag Model

The model assumes that a representative agent maximizes:

$$
E_{0}\left[(1-A)^{-1} \sum_{t=0}^{\infty} \beta^{t} C_{t}^{1-A}\right]
$$

where $c_{t}-c_{t}+b_{1} c_{t-1}+b_{2} c_{t-2}$ and $c_{t}$ is consumption expenditures at date $t .{ }^{t} A$ is the concavity parameter, $\beta$ is the rate of time discount, and $b_{1}$ and $b_{2}$ are the parameters representing habit persistence or durability. The vertical axis is the right-tail probability value for the generalized method of moments objective function, minimized over the choice of the parameters $A$ and $\beta$, for fixed values of $b_{1}$ and $b_{2}$. The negative of the $b$-values are shown on the other two axes. Negative values of the $b^{\prime} s$ (positive numbers on the axes) indicate habit persistence and positive values of the $b$ 's indicate durability of goods. The quarterly real asset returns are common stocks from size deciles 1,5 , and 10 , a long term government bond and the return to rolling over one-month treasury bills for 1948:2-1986:2 (153 observations). The real returns are the nominal returns deflated by the nondurables price deflator. The consumption data are real, per capita expenditures for consumer nondurable goods ( $\mathrm{X}-11$ adjusted). 


\section{Table 7}

Tests Results Using Quarterly Data for 1948:2-1986:2 (153 observations) and Seasonal Adjustment via Dummy Variables. The model assumes that a representative agent maximizes:

$$
E_{0}\left[(1-A)^{-1} \sum_{t=0}^{\infty} \beta^{t} C_{t}^{1-A}\right]
$$

where $c_{t}-c_{t}+b_{1} c_{t-1}$ and $c_{t}$ is consumption expenditures for nondurable goods at date $t$. A is the concavity parameter, $\beta$ is the rate of time discount, and $b_{1}$ is the parameter representing habit persistence $\left(b_{1}<0\right)$ or durability $\left(b_{1}>0\right)$. Estimation is by generalized method of moments (GMM). Asymptotic standard errors are in parentheses. P-value is the probability that a $x^{2}$ variate exceeds the minimized sample value of the GMM criterion function. The instrumental variables are a constant and the eight variables sumnarized in Figure 1. DecN is the real return of common stocks from market value decile $N$. The real returns are the nominal returns deflated by the nondurables price deflator.

\begin{tabular}{|c|c|c|c|c|c|c|}
\hline & & $\beta$ & A & $\mathrm{b}_{1}$ & $x^{2}$ & $p$-value \\
\hline System: & $\begin{array}{l}\text { Treasury Bill } \\
\text { Government Bond } \\
\text { Stocks: Decl } \\
\text { Stocks: Dec5 } \\
\text { Stocks: Dec10 }\end{array}$ & $\begin{array}{c}0.997 \\
(0.001) \\
0.926 \\
(0.061)\end{array}$ & $\begin{array}{c}0.441 \\
(0.235) \\
1.724 \\
(1.833)\end{array}$ & $\begin{array}{l}=0^{a} \\
-0.791 \\
(0.113)\end{array}$ & $\begin{array}{l}57.97 \\
39.54\end{array}$ & $\begin{array}{l}0.063 \\
0.579\end{array}$ \\
\hline System: & $\begin{array}{l}\text { Treasury Bill } \\
\text { Stocks: Declo }\end{array}$ & $\begin{array}{c}0.998 \\
(0.001) \\
0.946 \\
(0.044)\end{array}$ & $\begin{array}{c}0.213 \\
(0.238) \\
3.104 \\
(4.496)\end{array}$ & $\begin{array}{l}=0 \\
-0.621 \\
(0.261)\end{array}$ & $\begin{array}{l}37.89 \\
23.31\end{array}$ & $\begin{array}{l}0.001 \\
0.078\end{array}$ \\
\hline
\end{tabular}

a An "mo" Indicates that the parameter is set to zero. 


\section{Table 8}

Tests Results Using Consumer durable goods expenditures. The model assumes that a representative agent maximizes:

$$
E_{0}\left[(1-A)^{-1} \sum_{t=0}^{\infty} \beta^{t} C_{t}^{1-A}\right]
$$

where $c_{t}-c_{t}+b_{1} c_{t-1}$ and $c_{t}$ is consumption expenditures at date $t$. A is the concavity parameter, $\beta$ is the rate of time discount, and $b_{1}$ is the parameter representing habit persistence $\left(b_{1}<0\right)$ or durability $\left(b_{1}>0\right)$. Estimation is by generalized method of moments (GMM). Asymptotic standard errors are in parentheses. P-value is the probability that a $x^{2}$ variate exceeds the minimized sample value of the GMM criterion function. The instrumental variables are a constant and the eight variables summarized in Figure 1 . DecN is the real return of common stocks from market value decile $\mathrm{N}$.

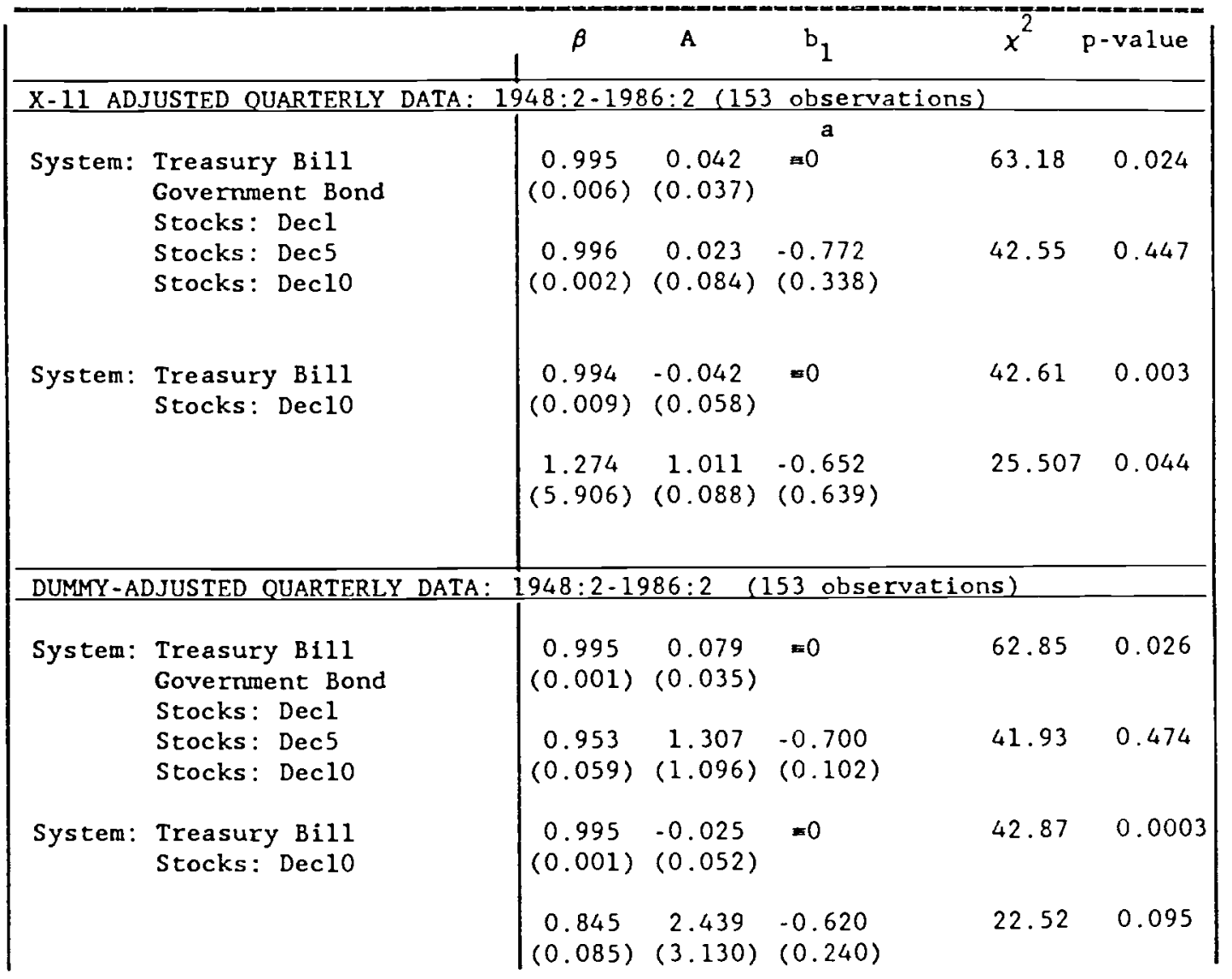


table 8 page 2

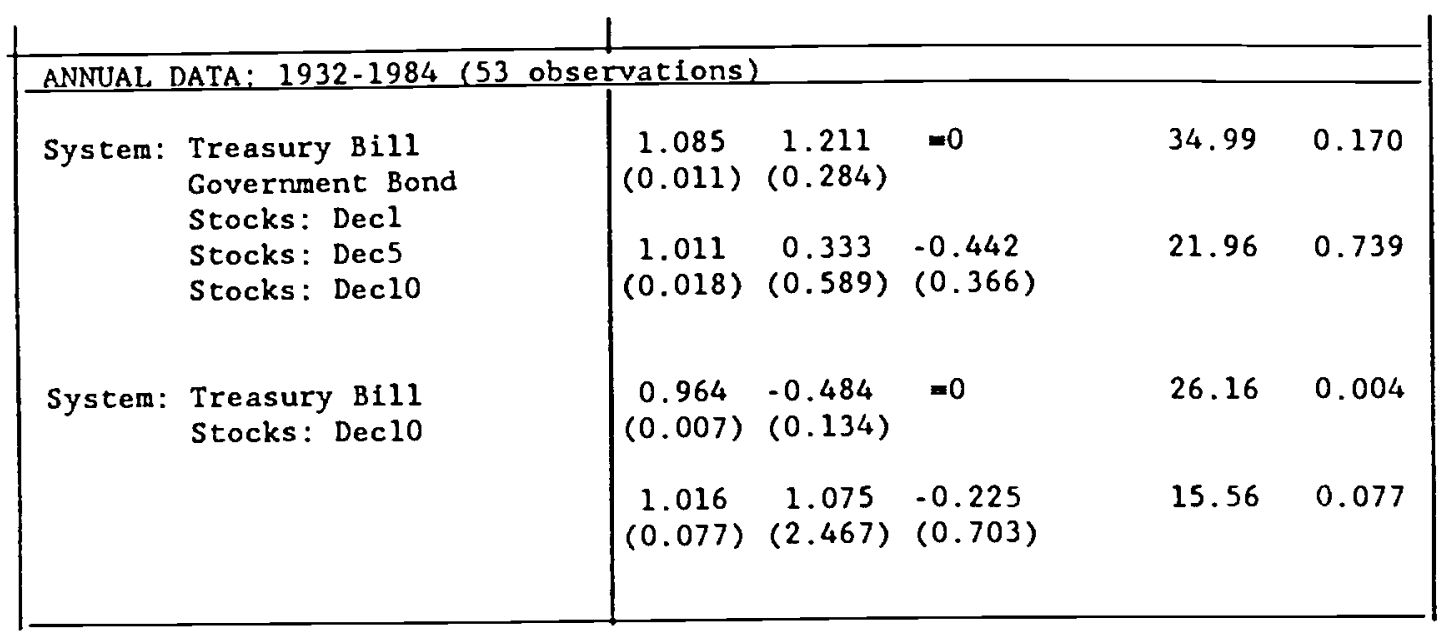

a An "mo" indicates that the parameter is set to zero. 


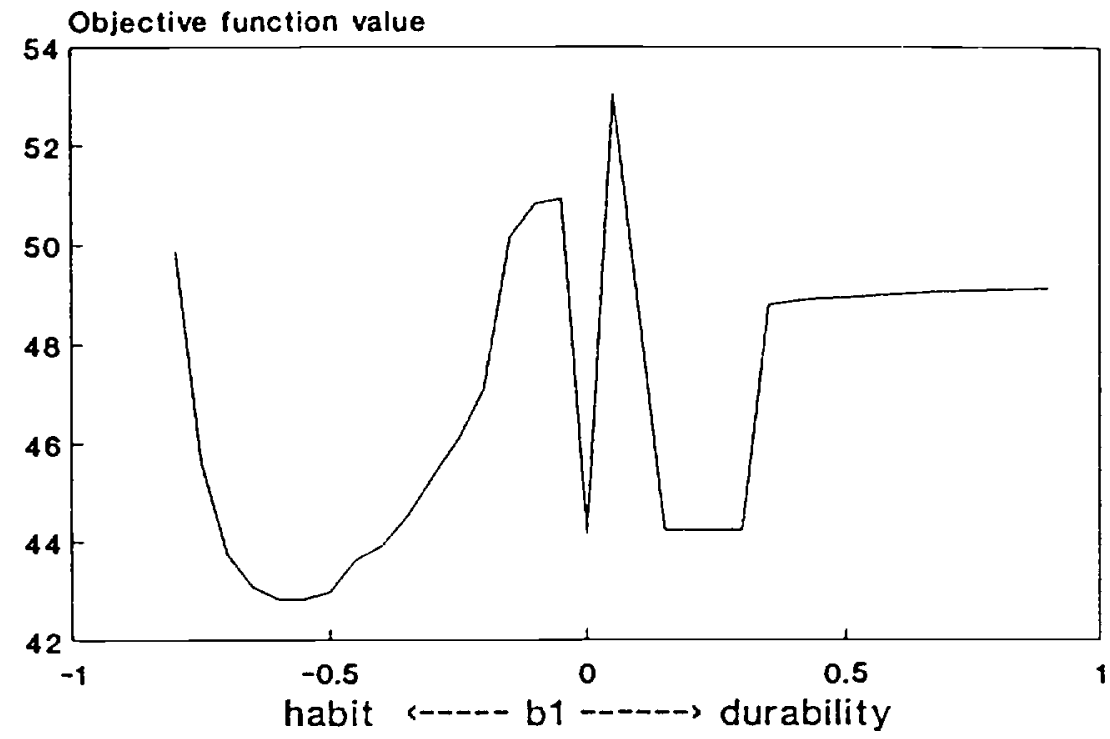

Figure 4: Sensitivity of the Objective Function to the Nonseparability Parameter in a One-lag Model with Durable Goods Expenditures

The $y$-axis is the value of the generalized method of moments objective function, minimized over the choice of the parameters $A$ and $\beta$, for given values of $b_{3}$. The $b_{1}$ values are shown on the $x$-axis. Negative values indicate habit persistence and positive values indicate durability of goods. The model assumes that a representative agent maximizes:

$$
E_{0}\left[(1-A)^{-1} \sum_{t=0}^{\infty} \beta^{t} C_{t}^{1-A}\right]
$$

where

$$
c_{t}-c_{t}+b_{1} c_{t-1}
$$

and $c_{t}$ is consumption expenditures at date $t$.

The consumption data are quarterly expenditures for consuner durable goods (seasonally adjusted by $X-11$ ). The real asset returns are common stocks from size deciles 1,5 , and 10 , a long term government bond and the return to rolling over one-month treasury bills for 1948:2-1986:2 (153 observations). The real returns are the nominal returns deflated by the consumer nondurables price deflator. 
Tests Results Using Unconditional Moment Restrictions. The model assumes that a representative agent maximizes:

$$
E_{0}\left[(1-A)^{-1} \sum_{t=0}^{\infty} \beta^{t} C_{t}^{1-A}\right]
$$

where $c_{t}-c_{t}+b_{1} c_{t-1}$ and $c_{t}$ is consumption expenditures at date $t$. A is the concavity parameter, $\beta$ is the rate of time discount, and $b_{1}$ is the parameter representing habit persistence $\left(b_{1}<0\right)$ or durability $\left(b_{1}>0\right)$. Estimation is by generalized method of moments (GMM). Asymptotic standard errors are in parentheses. P-value is the probability that a $x^{2}$ variate exceeds the minimized sample value of the GMM criterion function. The instrumental variable is a constant vector of ones. DecN is the real return of common stocks from market value decile $N$. The real returns are the nominal returns deflated by the nondurables price deflator.

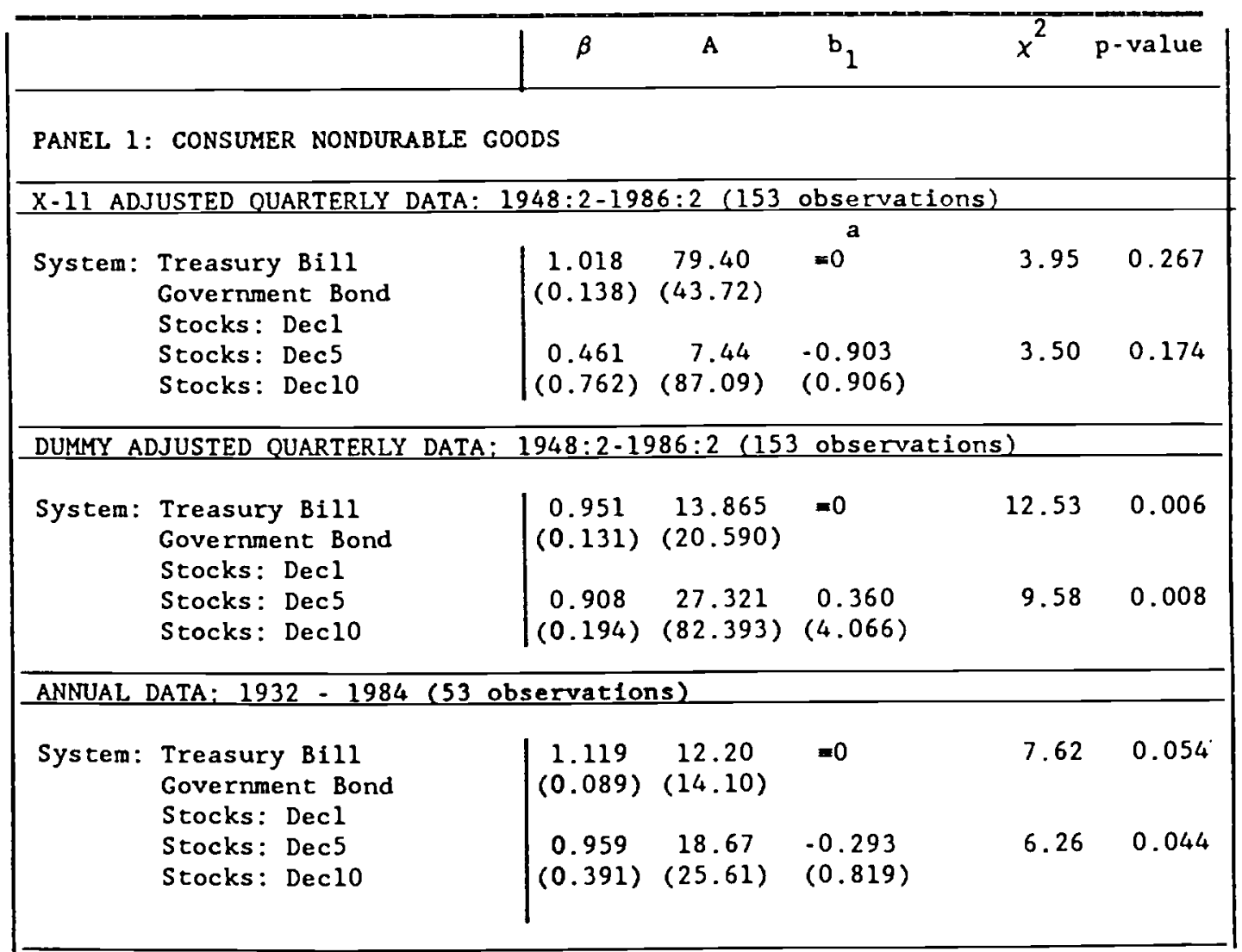


PANEL 2: CONSUMER DURABLE GOODS

X-11 ADJUSTED QUARTERLY DATA: $1948: 2-1986: 4$ (153 observations)

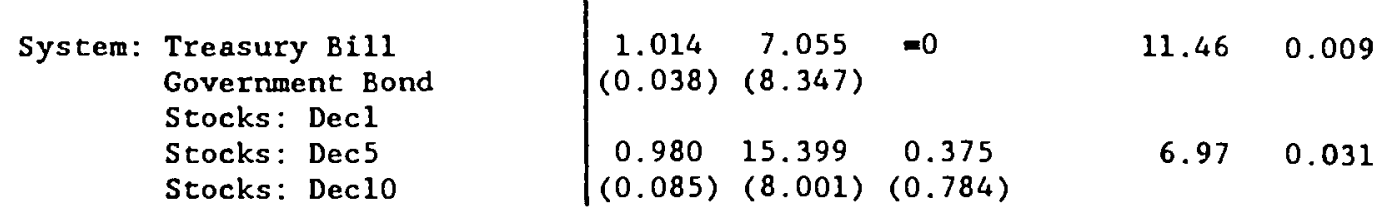

DUMMY ADJUSTED QUARTERLY DATA: $1948: 2-1986: 2$ (153 observations)

\begin{tabular}{|c|c|c|c|c|c|}
\hline System: & $\begin{array}{l}\text { Treasury Bill } \\
\text { Government Bond } \\
\text { Stocks: Decl } \\
\text { Stocks: Dec5 } \\
\text { Stocks: Dec10 }\end{array}$ & $\begin{array}{cc}0.970 & 4.633 \\
(0.093) & (7.644) \\
& \\
0.895 & 11.797 \\
(0.228) & (15.395)\end{array}$ & $\begin{array}{c}0.352 \\
(0.803)\end{array}$ & 11.38 & 0.025 \\
\hline \multicolumn{6}{|c|}{ ANNUAL DATA: $1932-1984$ (53 observations) } \\
\hline System: & $\begin{array}{l}\text { Treasury Bill } \\
\text { Government Bond } \\
\text { Stocks: Decl } \\
\text { Stocks: Dec5 } \\
\text { Stocks: Dec } 10\end{array}$ & $\begin{array}{cc}0.531 & -6.206 \\
(0.131) & (1.945) \\
& \\
1.039 & 1.461 \\
(0.057) & (11.06)\end{array}$ & $\begin{array}{l}=0 \\
0.476 \\
(19.42)\end{array}$ & 10.79 & 0.013 \\
\hline
\end{tabular}

a An $"=0$ indicates that the parameter is set to zero. 
Models with unrestricted mean Treasury bill returns: Quarterly Data, 1948:21986:2 (153 observations). The model assumes that a representative agent maximizes:

$$
E_{0}\left[(1-A)^{-1} \sum_{t=0}^{\infty} \beta^{t} C_{t}^{1-A}\right]
$$

where $c_{t}-c_{t}+b_{1} c_{t-1}$ and $c_{t}$ is consumption expenditures at date $t$. A is the concavity parameter, $\beta$ is the rate of time discount, and $b_{1}$ is the parameter representing habit persistence $\left(b_{1}<0\right)$ or durability $\left(b_{1}>0\right)$. The real Treasury bill return in the model is replaced by the real return plus the parameter, $L$, to leave the mean real return of the bill unrestricted. Estimation is by generalized method of moments (GMM). Asymptotic standard errors are in parentheses. $P$-value is the probability that a $x^{2}$ variate exceeds the minimized sample value of the GMM criterion function. The instrumental variables are a constant and the eight variables summarized in Figure 1 . DecN is the real return of common stocks from market value decile $\mathrm{N}$. The real returns are the nominal returns deflated by the nondurables price deflator.

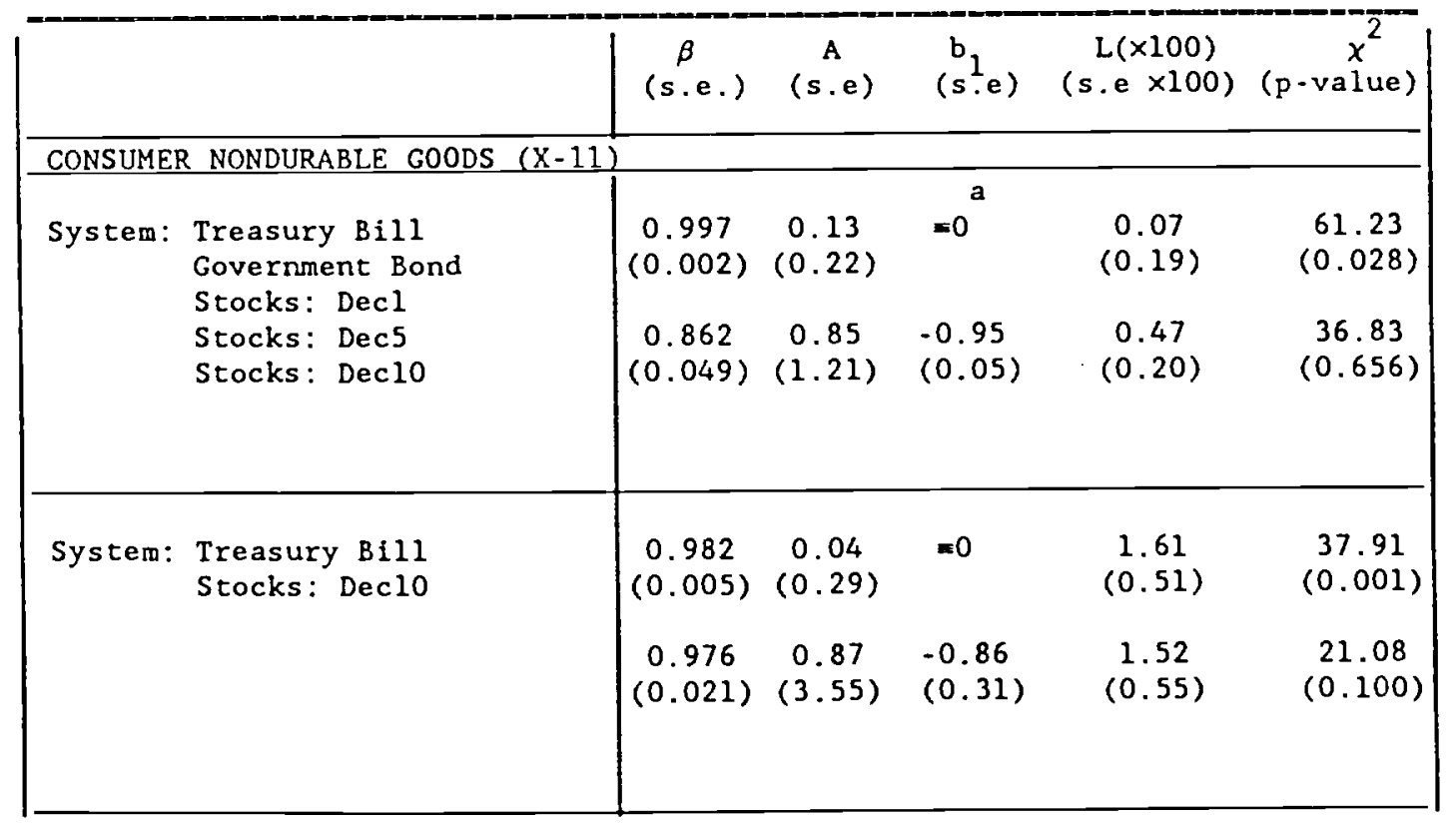

a An "=0" indicates that the parameter is set to zero. 